\title{
DISPONIBILIDADE DE CHUMBO NO SOLO RESULTANTE DO USO DE RESÍDUO-CORRETIVO E MATÉRIA ORGÂNICA
}

\section{GENELÍCIO CRUSOÉ ROCHA}

Engenheiro Agrônomo

Orientadora: Prof . Dr. ${ }^{\text {a }}$ MARIA EMÍlIA MATLAZZO-PREZOTTO

Dissertação apresentada à Escola Superior de Agricultura "Luiz de Queiroz", Universidade de São Paulo, para obtenção do título de Mestre em Agronomia, Área de Concentração: Solos e Nutrição de Plantas.

PIRACICABA

Estado de São Paulo - Brasil

Dezembro / 2000 
Dados Internacionais de Catalogação na Publicação (CIP) DIVISAOO DE BIBLIOTECA E DOCUMENTAÇAO - Campus "Luiz de QueIrOz"/USP

Rocha, Genelicio Crusoé

Disponibilidade de chumbo no solo resultante do uso de residuo-corretivo e matéria orgånica / Genelício Crusoé Rocha. - - Piracicaba, 2000.

$56 \mathrm{p}$.

Dissertaçăo (mestrado) - - Escola Superior de Agricultura Luiz de Queiroz, 2000. Bibliografia.

1. Acidez do solo 2. Corretivo agricola 3. Matéria orgânica 4. Metal pesado 5. Residuo industrial I. Titulo 
à Deus,

DEDICO

aos meus pais,

Jenelício G. Rocha e Elisa M. C. Rocha

irmãos,

Jeísa, Myrian, Iêda e Rodrigo

sobrinhos,

Ícaro, Iana, Vinícius, Matheus e Arthur

e à Karen,

OFEREÇO 


\section{AGRADECIMENTOS}

Agradeço a todos que diretamente ou indiretamente contribuíram para a realização desse trabalho e, em especial:

Aos Professores: Dra. Maria Emilia Matiazzo-Prezotto e Dr. Arnaldo Antônio Rodella, pela orientação, ensinamentos e dedicação dispensada;

Aos Professores: Dr. Edgard G. F. Beauclair, Dr. Luís F. Alleoni e Dra. Jussara B. Regitano pelas valiosas correções e sugestões;

Ao Centro de Energia Nuclear na Agricultura - CENA, especialmente ao Dr. Francisco Krug, e a sua equipe. Ao Instituto Agronômico de Campinas - IAC, especialmente à $\mathrm{Dr}^{\mathrm{a}}$. Mônica Abreu, pela colaboração na realização das análises químicas;

Aos colegas: Fábio Prata, Silvino Moreira e Tadeu C. Reis, pela ajuda substancial na realização desse trabalho;

Ao Prof. Dr. Joelito Rezende, pela amizade, dedicação, orientação e ensinamentos na iniciação científica;

Ao grande amigo e colega José Fernandes de Melo Filho, pelas orientações profissionais, ensinamentos, e por sempre acreditar no meu potencial;

Aos amigos: Adriana M. Pires, Cristiano Andrade, Fábio Prata, Jean Dalmo, Jeane C. Portela, Ramon Martinez e Tadeu C. Reis, pela sincera amizade, e a todos colegas do CPG em Solos e Nutrição de Plantas;

Aos Professores: Dr. A. Roque Dechen, Dr. Godofredo César Vitti, Dr. Jorge de Castro Kiehl, Dr. José Leonardo Gonçalves, Raymond Pakovsky, Quirino A. Carmello, pelos conhecimentos transmitidos durante o curso;

Ao Conselho Nacional de Pesquisa - CNPq, pelo suporte financeiro;

Ao laboratório de Química da Escola Superior de Agricultura "Luiz de Queiroz" pela estrutura e materiais cedidos e por tornar possível a realização desse trabalho. Aos funcionários: Angélica, Carlos, Lenita, Janaína, Nancy e Rita, pela ajuda no que precisei. 
Página

LISTA DE FIGURAS.......................................................................................... vi

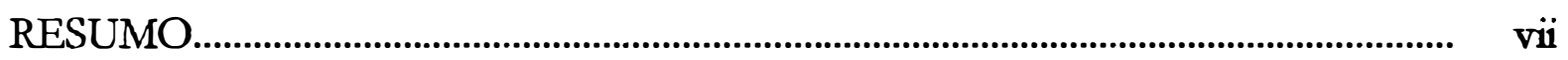

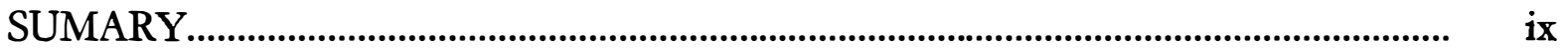

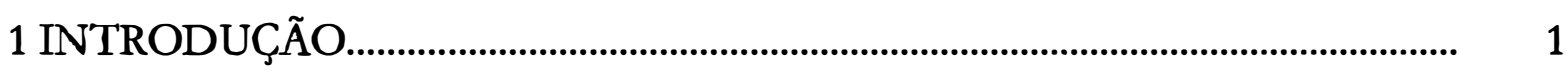

2 REVISÃO DE LITERATURA................................................................................. 3

2.1 Conceito de metal pesado.................................................................................................. 3

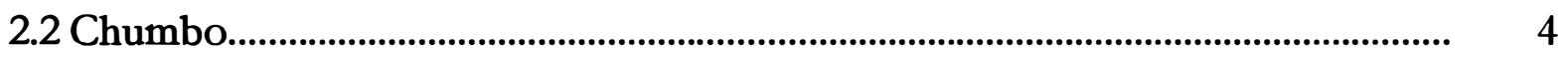

2.2.1 Fontes naturais e antropogênicas de chumbo no solo............................................ 5

2.2.1.1 Fontes naturais................................................................................................................. 5

2.2.1.2 Fontes antropogênicas........................................................................................ 5

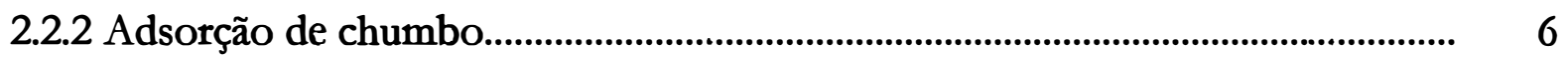

2.2.3 Influência do pH na adsorção de chumbo............................................................... 9

2.2.4 A matéria orgânica do solo e a disponibilidade de chumbo................................. 11

2.2.5 Absorção radicular de chumbo................................................................................ 13

2.2.6 Exsudados de raízes e absorção radicular de chumbo............................................ 14

2.3 Acidez do solo........................................................................................................ 16

2.3.1 Origem da acidez do solo..................................................................................... 16

2.3.2 Efeito da matéria orgânica na acidez do solo........................................................... 17

2.3.3 Efeito do $\mathrm{pH}$ no teor de $\mathrm{Al}$ trocável.......................................................................... 19

2.4 Cálcio e magnésio................................................................................................... 20

2.4.1 Efeito do $\mathrm{pH}$ na disponibilidade de $\mathrm{Ca}$ e $\mathrm{Mg}$............................................................. 21

2.4.2 Absorção radicular de Ca e Mg................................................................................... 22

2.4.3 Matéria orgânica como fonte de $\mathrm{Ca}$ e $\mathrm{Mg}$.................................................................. 23

3 MATERIAL E MÉTODOS................................................................................... 24

3.1 Caracterização do material utilizado................................................................................. 24

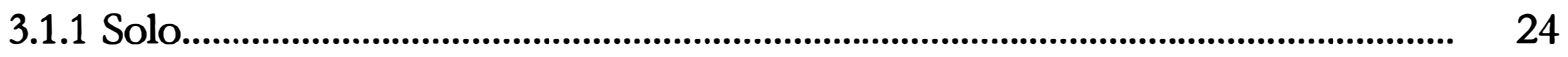




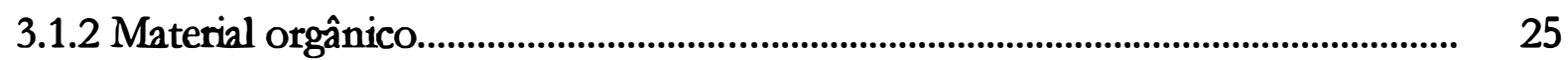

3.1.3 Residuo-corretivo................................................................................................. 26

3.2 Experimento de incubação.................................................................................. 27

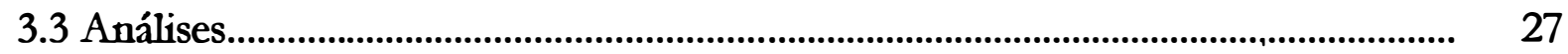

3.3.1 Cálcio, magnésio, alumínio e $\mathrm{pH}$........................................................................... 28

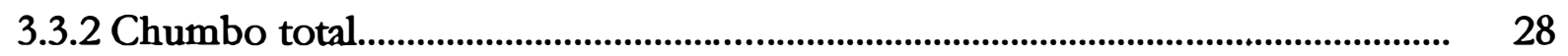

3.3.3 Chumbo trocável................................................................................................... 29

3.4 Biodisponibilidade do chumbo................................................................................... 30

3.4.1 Chumbo no material vegetal.................................................................................. 31

4 RESULTADOS E DISCUSSÃO......................................................................... 32

4.1 Resíduo-corretivo e material orgânico nos atributos do solo.................................... 32

4.2 Resíduo-corretivo e material orgânico nos teores de $\mathrm{Pb}, \mathrm{Ca}$ e $\mathrm{Mg}$ no material vegetal .................................................................................................................. 38

5 CONSIDERAÇÕES GERAIS........................................................................ 42

6 CONCLUSÃO....................................................................................................... 43

REFERÊNCIAS BIBLIOGRÁFICAS.................................................................. 44 


\section{LISTA DE FIGURAS}

Página

Figura 1. Teor de $\mathrm{Pb}$ total, em função da dose do resíduo aplicada, e do extrator.

Figura 2. Teores de chumbo trocável em função da dose do resíduocorretivo, sob adição de matéria orgânica.

Figura 3. Efeito da dose do resíduo-corretivo sobre o $\mathrm{pH}$, em função da dose de matéria orgânica adicionada.

Figura 4. Efeito da do se de resíduo-corretivo no teor de $\mathrm{Al}^{3+}$ trocável, sobre adição de matéria orgânica.

Figura 5. Teores de $\mathrm{Ca}^{2+}$ trocável em função da dose do resíduo-corretivo aplicada, sob adição de esterco bovino.

Figura 6. Influência da dose de esterco bovino(a) e resíduo-corretivo(b) no teor de $\mathrm{Mg}$.

Figura 7. Teor de chumbo absorvido em função da dose de resíduo-corretivo aplicada.


corretivo aplicada. 


\title{
DISPONIBILIDADE DE CHUMBO NO SOLO RESULTANTE DO USO DE RESÍDUO-CORRETIVO E MATÉRIA ORGÂNICA
}

\author{
Autor: GENELÍCIO CRUSOÉ ROCHA \\ Orientadora: Prof Dr. $^{\text {a }}$ MARIA EMÍLIA MATIAZZO-PREZOTTO
}

\section{RESUMO}

Nos últimos anos, a utilização de resíduos na agricultura têm sido incrementada devido ao crescimento populacional e industrial. Os resíduos da mineração de zinco e chumbo, conhecido comercialmente por calcário de Paracatú, têm sido utilizados em algumas regiões como alternativa para a correção da acidez dos solos. Esses tesíduos, além do Ca e do $\mathrm{Mg}$, apresentam metais pesados em sua constituição, principalmente $\mathrm{Pb}, \mathrm{Cd}$ e $\mathrm{Zn}$. Desta forma, este estudo tem como objetivos: (i) avaliar o comportamento do $\mathrm{Pb}$ aplicado no solo via resíduo-corretivo, sob efeito da variação do $\mathrm{pH}$ e da influência da matéria orgânica; (ii) avaliar os teores de $\mathrm{Ca}, \mathrm{Mg}$ e $\mathrm{Al}$ trocáveis, fitodisponibilidade do $\mathrm{Pb}, \mathrm{Ca}$ e $\mathrm{Mg}$, em função das doses aplicadas do resíduocorretivo e da matéria orgânica.

Para o estudo dos teores de $\mathrm{Pb}, \mathrm{Ca}, \mathrm{Mg}$ e $\mathrm{Al}$ trocáveis e $\mathrm{Pb}$ total, foram instalados experimentos de incubação, sob condições controladas de laboratório, 
mantendo-se a umidade do solo a $70 \%$ da capacidade de campo, em um esquema fatorial completo $5 \times 3$, correspondentes a 5 doses do resíduo-corretivo $(0,2,4,8$ e 12 t ha-1), e a 3 de matéria orgânica (esterco bovino 0,13 e $26 \mathrm{t} \mathrm{ha}^{-1}$ ). Os materiais foram incubados por 90 dias. Após este período, montou-se um experimento tipo "Neubauer" para avaliar-se a fitodisponibilidade do $\mathrm{Pb}, \mathrm{Ca}$ e $\mathrm{Mg}$.

As maiores doses do tesíduo-corretivo, associadas às maiores de matéria orgânica, reduziram o $\mathrm{Pb}$ trocável no solo e aumentou os teores de $\mathrm{Ca}$ e $\mathrm{Mg}$ trocáveis, porém, o teor de $\mathrm{Pb}$ absorvido foi maior para a maior dose do resíduo-corretivo, devido a provável liberação de exsudados de raízes solubilizando o metal, sem que houvesse influência da matéria orgânica, porém, a presença da matéria orgânica aumentou a absorção de $\mathrm{Ca}$ e de $\mathrm{Mg}$ e impediu a relativa elevação do $\mathrm{pH}$ no solo. Observou-se diminuição no teor de $\mathrm{Al}$ trocável no solo causada pelo aumento do $\mathrm{pH}$, e pelo aumento da matéria orgânica do solo. 


\title{
SOIL LEAD AVAILABILITY AS A RESULT OF CORRECTIVE-RESIDUE AND ORGANIC MATTER USES
}

\author{
Author: GENELÍCIO CRUSOÉ ROCHA \\ Adviser: Prof ${ }^{a}$ Dr. ${ }^{2}$ MARIA EMÍLIA MATIAZZO-PREZOTTO
}

\section{SUMMARY}

In the last years, the use of residues in the agriculture has increased due to the population growth in the world. Lead and zinc mining residue, known commercially as lime of Paracatú has been used in some Brazilian agricultural regions an alternative to the correct soils acidity. This residue, besides $\mathrm{Ca}$ and $\mathrm{Mg}$, presents heavy metals in its constitution, mainly $\mathrm{Pb}, \mathrm{Cd}$ and $\mathrm{Zn}$. This study has the objective: (i) of evaluating the behavior of $\mathrm{Pb}$ applied in the soil via corrective-residue, as affected by $\mathrm{pH}$ and organic matter and (ii) the amount of exchangeable $\mathrm{Ca}, \mathrm{Mg}$ and $\mathrm{Al}$, and $\mathrm{Pb}, \mathrm{Ca}$ and $\mathrm{Mg}$ phythoavailability.

To evaluate the amounts of exchangeable $\mathrm{Pb}, \mathrm{Ca}, \mathrm{Mg}$ and $\mathrm{Al}$ and total $\mathrm{Pb}$, incubation experiments were installed, under laboratory controlled conditions, maintaining the soil water content at approximately in the field capacity, in a fatorial $5 \times 3$ statistical design, corresponding to 5 doses of the corretive-residue $\left(0,248\right.$ and $\left.12 \mathrm{t} \mathrm{ha}^{-1}\right)$, and 3 doses of organic matter (bovine manure 0,13 and $26 \mathrm{t} \mathrm{ha}^{-1}$ ). Materials were incubated by 90 days 
and after this period, the incubated soil samples were used in a "Neubauer" experiment type to evaluate $\mathrm{Pb}, \mathrm{Ca}$ and $\mathrm{Mg}$ phythoavailability.

The higher doses of the corrective-residue, associated to the amount of organic matter, reduced exchangeable $\mathrm{Pb}$ in the soil, and it increased the amount of exchangeable $\mathrm{Ca}$ and $\mathrm{Mg}$, even thought the amounts of absorbed $\mathrm{Pb}$ have been greater for the higher corrective-residue doses. The presence of the organic matter increased the absorption of $\mathrm{Ca}$ and $\mathrm{Mg}$ and presented the relative elevation of the $\mathrm{pH}$ in the soil. For the soil exchangeable $\mathrm{Al}$ there was a decrease in its amount caused by the increase of the $\mathrm{pH}$ and the increase of the amount organic matter. 


\section{INTRODUÇÃo}

Os corretivos da acidez do solo são fundamentais no aumento da produtividade das culturas, em solos sob clima tropical. Esses insumos neutralizam o alumínio trocável, fornecem cálcio e magnésio, aumentam a disponibilidade de diversos outros nutrientes e garantem a presença de cátions trocáveis em níveis adequados para o crescimento e desenvolvimento das plantas. No Brasil, o corretivo mais utilizado é o calcário dolomítico, contudo, alguns resíduos industriais têm sido utilizado com a mesma finalidade.

A utilização de resíduos urbanos e industriais na agricultura vem sendo incrementado nos últimos anos em função do alto crescimento populacional e industrial, gerando uma maior produção desses resíduos. Os resíduos da mineração de zinco e chumbo têm sido utilizados em algumas regiões agrícolas dos Estados de Minas Gerais e Goiás, como alternativa para a correção da acidez dos solos. Contudo, esses resíduos podem apresentar metais pesados, sendo necessário o estudo da contribuição desses resíduos como fonte de metais pesados.

A maioria dos solos das regiões tropicais, devido a seu material de origem e grau de intemperismo, normalmente, necessita de considerável quantidade de corretivos de acidez e de fertilizantes fosfatados, o que é motivo de grande preocupação em regiões onde a correção dos solos é realizada através de resíduos contaminados por metais pesados.

A contaminação dos solos por metais pesados via aplicação de resíduos, tem se tornado de grande importância nos últimos anos, devido ao fato dessa prática 
estar se tornando cada vez mais comum no mundo. A aplicação de grandes quantidades desses resíduos pode levar a ocorrência de problemas ambientais nos solos.

Quando se considera o uso agtonômico de resíduos contendo metais pesados, devem ser feitas previsões de seu comportamento nos solos e, nesse aspecto, a preocupação mais freqüente diz respeito à solubilização, com conseqüente caminhamento desses metais em direção ao lençol freático e biodisponibilidade para vegetais, com conseqüuente entrada do metal na cadeia alimentar.

A disponibilidade do chumbo presente no resíduo carbonatado é função direta da dose aplicada, uma vez que a contaminação do solo por chumbo proveniente do produto está diretamente relacionada com a elevação do $\mathrm{pH}$, assim como o teor de matéria orgânica no solo, o qual pode diminuir significativamente a atividade do íon $\mathrm{Pb}$ na solução do solo, reduzir o teor de alumínio trocável, além de aumentar a disponibilidade de cálcio e magnésio.

O objetivo desse trabalho foi, portanto, avaliar o comportamento do chumbo aplicado no solo via resíduo carbonatado, sob efeito da variação do $\mathrm{pH}$ e da influência da adição da matéria orgânica. Paralelamente, avaliou-se os teores de cálcio, magnésio e alumínio trocáveis em função da dose aplicada do resíduocorretivo e da adição de matéria orgânica. 


\section{REVISÃO DE LITERATURA}

\subsection{Conceito de metal pesado}

A expressão "metal pesado" se aplica a elementos que tem massa espećifica maior que $5 \mathrm{~g} \mathrm{~cm}^{-3}$ ou que possuem um número atômico maior que 20 . A expressão engloba metais, semi-metais e mesmo não metais como o selênio. Às vezes, usa-se como sinônimos, tais como "elementos traços" ou "metais traços", os quais também não são adequados visto que o qualificativo "traço" em química analítica quantitativa é reservado para designar concentrações ou teores de qualquer elemento que não podem ser quantificados pelo método empregado na sua determinação. Imprópria ou não, a expressão "metal pesado" parece ter sido a mais usada para designar metais classificados como poluentes do ar, água, solo, alimentos e forragens (Malavolta, 1994).

Alguns dos metais pesados são elementos essenciais aos vegetais $(\mathrm{Cu}, \mathrm{Fe}$, $\mathrm{Mn}, \mathrm{Mo}, \mathrm{Zn}$ e o Ni para algumas leguminosas), outros são benéficos ao crescimento das plantas ( $\mathrm{Co} \mathrm{eV}$ ) e outros não são essenciais ou não apresentam função ( $\mathrm{Al}, \mathrm{Cd}$, Cr, Hg e Pb). Segundo Malavolta (1994), o Co já poderia ser incluído na categoria dos elementos essenciais, uma vez que satisfaz tanto os critérios diretos como indiretos de essencialidade, pois participa na composição da colamina e tem função na atividade de enzimas como desidratases, mutases, fosforilases e transferases. 


\subsection{Chumbo}

Membro do grupo IV A da tabela periódica, o chumbo possui o número atômico 82 e dois estados de oxidação ( $\mathrm{Pb}$ II e $\mathrm{Pb} \mathrm{IV}$ ), mas a química ambiental do elemento é dominada pelo íon $\mathrm{Pb}^{2+}$. O chumbo elementar é um metal denso, $11,3 \mathrm{~g}$ $\mathrm{cm}^{-3}$, funde-se a $327^{\circ} \mathrm{C}$ e entra em ebulição a $1744^{\circ} \mathrm{C}$. Esse baixo ponto de fusão tem lhe permitido ser fundido, moldado e trabalhado desde sociedades primitivas (Adriano, 1986).

O chumbo é relativamente opaco a radiação ionizante, e serve como valioso escudo em trabalhos com raios-X e radioisótopos. Também é utilizado para fazer placas de baterias acumuladoras e munições em geral, além de estar presente em pigmentos.

Pesticidas a base de arsenato de chumbo, $\mathrm{PbHAsO}_{4}$, foram aplicados em pomares, durante muito tempo, para o controle de insetos, o que sugere que os solos destes pomares contenham elevados teores deste metal. $O$ uso comercial desses produtos atualmente tem sido restringido, sendo substituído por pesticidas orgânicos.

No aspecto da química ambiental, os compostos com chumbo tendem a se acumular nos solos e sedimentos, além de serem tóxicos para mamíferos, sendo que seu acúmulo pode causar problemas mentais, principalmente em crianças.

$\mathrm{O}$ raio iônico do $\mathrm{Pb}^{2+}$ é $124 \mathrm{pm}$, muito parecido com o $\mathrm{K}^{+}, 133 \mathrm{pm}$. Isso lhe permite a substituição isomórfica do $\mathrm{K}^{+}$nos silicatos, o que também ocorre com o $\mathrm{Ca}^{2+}$, em carbonatos e apatitas, por apresentarem raio iônico de 106 pm. Uma grande afinidade pelo enxofre, também é atribuido ao $\mathrm{Pb}^{2+}$, motivo pelo qual ele é muito encontrado em rochas que contém esse elemento (Adriano, 1986). 
2.2.1 Fontes naturais e antropogênicas de chumbo no solo

A presença do $\mathrm{Pb}$ no solo é explicada pela contribuição natural do material de origem e por diversas fontes antropogênicas.

\subsubsection{Fontes naturais}

A quantidade de metais pesados num solo, sem interferência antropogênica, depende do teor destes na rocha de origem e do grau de intemperização que esse material sofreu (Malavolta, 1994). Os metais podem estar na forma solúvel, trocável, fixada aos colóides minerais do solo, precipitada com outros componentes, na biomassa microbiana ou complexada com a matéria orgânica.

Todas as rochas da crosta terrestre contém $\mathrm{Pb}$ : eruptivas básicas (basalto, gabro) - $8 \mathrm{mg} \mathrm{kg}^{-1}$; eruptivas ácidas (granito, riolito) - $20 \mathrm{mg} \mathrm{kg}^{-1}$; intermediárias (diorito, andesita), metamórficas (xistos), certas sedimentares (argilitos) - 15 a $20 \mathrm{mg}$ $\mathrm{kg}^{-1}$ e calcários e arenitos $7-10 \mathrm{mg} \mathrm{kg}^{-1}$. Na Litosfera, a concentração do material é da ordem de $16 \mathrm{mg} \mathrm{kg}^{-1}$ (Malavolta, 1994).

A galena, $\mathrm{PbS}$, é o principal minério de chumbo, porém outros minérios podem conter esse elemento. A ocorrência de galena é comum em veios, associada a blenda, pirita, dolomita, calcita, quartzo, barita e fluorita (Dana, 1978).

\subsubsection{Fontes antropogênicas}

Adriano (1986) compilou dados sobre as adições antropogênicas de chumbo. O total anual é, ou era, da ordem de $400.000 \mathrm{t}$, sendo que desse total $70 \%$ 
eram representadas por aditivos de gasolina. Os EUA foram responsáveis por cerca de $180.000 \mathrm{t}$, número que deve ter diminuído em função de restrições ao uso da gasolina- $\mathrm{Pb}$ em veículos novos. Indústrias de outros metais como $\mathrm{Fe}, \mathrm{Zn} \mathrm{e} \mathrm{Cu}$, adicionam $113.000 \mathrm{t}$ ao ano, e a queima de carvão adiciona outros $15.000 \mathrm{t}$.

Os poluentes adicionados na atmosfera pelos veículos e pelas indústrias podem ser levados muito longe e depositados pela chuva - como acontece na floresta tropical úmida da Venezuela. Altos níveis de $\mathrm{Pb}$, e de outros metais pesados, estão contidos no esgoto e no lodo de origem industrial (Berton, 2000).

\subsubsection{Adsorção de chumbo}

A retenção dos metais pesados no solo está ligada a processos de acúmulo e transporte dessas espécies que dependem, em grande parte, das interações das mesmas com a fase sólida do sistema. Tal interação é bastante complexa, envolvendo reações de adsorção/dessorção, precipitação/dissolução, complexação e oxi-redução, tanto com a fase inorgânica, quanto com a fase orgânica das mesmas (Sposito, 1989 e Alloway, 1990).

A atividade de um determinado metal na solução do solo é determinada pelo seu equilíbrio entre as partículas de argila, matéria orgânica, hidróxidos de $\mathrm{Fe}$, Al e Mn e quelantes solúveis. As reações de adsorção ocorrem, normalmente, na fração argila do solo, sendo que os óxidos de alumínio, ferro e manganês e os grupos funcionais ácidos da matéria orgânica são as superficies reativas mais representativas. Estes componentes apresentam as maiores superficies especificas e, portanto, os maiores superficies de contatos com a solução do solo (Tan, 1993).

De acordo com Sposito (1989), para que haja movimentação e lixiviação de metais, e também sua entrada na cadeia alimentar, é necessário que os 
mesmos estejam presentes na solução do solo, ou associados a partículas móveis. Isso vai depender da interação entre as reações químicas existentes no solo quando da adição do metal.

Matiazzo-Prezotto (1994), trabalhando em condições de laboratório com quatro diferentes tipos de solos em 2 valores de $\mathrm{pH}$, onde os metais $\mathrm{Cu}, \mathrm{Cd}, \mathrm{Cr}, \mathrm{Ni}$ e Zn foram adicionados sob forma de soluções, observou que o conteúdo de óxidos de Fe e Al presentes apresentou importante papel na prevenção da passagem dos metais pesados para a solução do solo, onde estariam mais sujeitos à lixiviação e à absorção pelas plantas.

Os óxidos e hidróxidos de Fe e de Al são importantes constituintes do solo, principalmente em solos muito intemperizados como os de regiões sob clima tropical. Esses constituintes apresentam em suas superficies, sítios de altas energias de ligação para a adsorção de metais pesados (Anderson \& Christensen, 1998). Os grupamentos hidroxila que aparecem na superficie dos óxidos podem estar ligados a um, dois ou até três metais na estrutura do mineral, podendo formar quelados (Fontes, 1996).

A adsorção dos metais aos óxidos dos solos pode ocorrer por forças eletrostáticas ou por meio da formação de ligações covalentes com o $\mathrm{O}$ na superficie desses colóides. $\mathrm{Da}$ mesma forma que ocorre para as argilas 1:1, essas ligações são afetadas pelo $\mathrm{pH}$ do solo.

Acredita-se que os altos teores de argila e de óxidos de $\mathrm{Fe}, \mathrm{Al}$ e $\mathrm{Mn}$ do solo, a calagem e o maior tempo de incubação diminuam a biodisponibilidade de metais pesados.

A afinidade dos metais pela superficie dos óxidos é dada de acordo com a tendência de formarem íons metálicos hidratados. Gadde \& Laitinen (1974) verificaram que a ordem de adsorção em óxidos de $\mathrm{Mn}$ e de $\mathrm{Fe}$ é: $\mathrm{Pb}^{2+}>\mathrm{Zn}^{2+}=$ $\mathrm{Cd}^{2+}$. Forbes et al. (1976) verificaram a seguinte ordem de afinidade na superficie da goetita: $\mathrm{Cu}^{2+}>\mathrm{Pb}^{2+}>\mathrm{Zn}^{2+}>\mathrm{Co}^{2+}>\mathrm{Cd}^{2+}$. Já Kinniburg et al. (1976) observaram a 
seguinte ordem de afinidade para os hidróxidos de $\mathrm{Fe}$ amorfos: $\mathrm{Pb}>\mathrm{Cu}>\mathrm{Zn}>\mathrm{Ni}$ $>\mathrm{Cd}>\mathrm{Sr}>\mathrm{Mg}$ e para os hidróxidos de alumínio: $\mathrm{Cu}>\mathrm{Pb}>\mathrm{Zn}>\mathrm{Ni}>\mathrm{Co}>\mathrm{Cd}$. Pode-se concluir, portanto, que o $\mathrm{Pb}$ e o $\mathrm{Cu}$ são os metais pesados mais fortemente adsorvidos. Recentemente, Fontes et al. (2000) observaram maior adsorção para Cu e $\mathrm{Pb}$ comparado ao $\mathrm{Cd}$ e $\mathrm{Zn}$, em estudos de adsorção competitiva para 3 solos brasileiros. Esses resultados são semelhantes aos encontrados por Burak et al. (2000). Segundo Alleoni (2000), as cargas negativas da superficie dos óxidos podem atrair cátions eletrostaticamente, sendo estas em menores quantidades, porque nos valores de $\mathrm{pH}$ normalmente encontrados em solos tropicais (entre 4,0 e 6,5), a superficie dos óxidos apresenta cargas positivas. Assim, o fenômeno de adsorção não pode ser explicado simplesmente por forças eletrostáticas. Desta forma a adsorção de metais pesados em óxidos e hidróxidos é governada por ligação covalente e especifica (Forbes et al., 1976; Lothenbach et al., 1997).

A primeira tentativa de estabelecimento de critérios para nortear a quantidade de resíduos contendo metais, possível de ser adicionada a solos sob clima tropical, foi sugerida por Matiazzo-Prezotto (1994). De acordo com o autor, o conteúdo de argila e de óxidos de $\mathrm{Fe}$ e $\mathrm{Al}$ devem ser as variáveis consideradas. Solos com teor de argila inferiores a $7 \%$ e conteúdo de óxidos de $\mathrm{Fe}$ e $\mathrm{Al}$ inferiores a $3 \%$ são inadequados para a aplicação de resíduos contendo metais. Vale ressaltar que a sistemática foi proposta com base em um trabalho desenvolvido com metais adicionados a solos com diferentes classes texturais, sob forma de sais solúveis, que é a condição de maior solubilidade dos metais.

Um agravante para as condições tropicais é que a acidez natural dos solos, juntamente com a acidez gerada através da adição de alguns fertilizantes e os menores valores de $\mathrm{pH}$ encontrados na rizosfera de algumas plantas, pode contribuir para que o potencial poluidor desses metais seja maior nessas condições do que em regiões sob clima temperado (Powell et al., 1981). 


\subsubsection{Influência do pH na adsorção de chumbo}

Embora a solubilidade dos metais dependa da forma que esses se encontram no solo, o $\mathrm{pH}$ é uma das características do solo que mais afeta a solubilidade. As reações de precipitação, complexação e adsorção são favorecidas pela elevação do $\mathrm{pH}$ (Sposito, 1989). À medida que o $\mathrm{pH}$ aumenta, a solubilidade do $\mathrm{Pb}$ diminui (Albasel \& Cottenie, 1985; Artega, 1996; Berton, 2000). Segundo Melo et al. (1997), a elevação do $\mathrm{pH}$ promove a formação de precipitados na forma de hidróxidos, fosfatos e carbonatos de $\mathrm{Pb}$ e de complexos insolúveis com a matéria orgânica.

Estudos sobre mobilidade e biodisponibilidade têm demonstrado que os metais $\mathrm{Pb}, \mathrm{Cr}$ e $\mathrm{Cu}$ são menos móveis, ao contrário do $\mathrm{Zn}, \mathrm{Ni}$, Mn e principalmente $\mathrm{Cd}$, os quais, consequentemente, apresentam maior risco de contaminação do meio (Tyler et al., 1989; Amaral Sobrinho et al., 1992; Amaral Sobrinho, 1993). Sob condições de menores valores de $\mathrm{pH}$, os metais ocorrem, preferencialmente, em formas mais solúveis e, quando associados a formas mais estáveis podem ser solubilizados pelo abaixamento desses valores.

Alguns autores citam o $\mathrm{pH}$ como um fator importante nas reações de adsorção entre a superfície do colóide e cátions metálicos (Amaral Sobrinho et al. 1992; Sanders \& Sparks, 1995; King 1996 e Camargo 1997). O pH do solo pode afetar a quantidade de cargas na superficie, além da forma dos íons presentes e, por essa razão, exerce importante influência na adsorção de cátions pelo solo. Segundo Abd-Elfattah \& Wada (1981), o $\mathrm{Pb}$ e o $\mathrm{Cu}$ são mais afetados pelo aumento do $\mathrm{pH}$ em relação ao Cd, Zn e Co.

Santillan-Medrano \& Jurinak (1975), apresentaram dados sugestivos de que, em solos não calcáreos, a solubilidade do $\mathrm{Pb}^{2+}$ apresenta-se regulada por 
$\mathrm{Pb}(\mathrm{OH})_{2}, \mathrm{~Pb}_{3}\left(\mathrm{PO}_{4}\right)_{2}, \mathrm{~Pb}_{3}\left(\mathrm{PO}_{4}\right)_{2}, \mathrm{~Pb}_{4} \mathrm{O}\left(\mathrm{PO}_{4}\right)_{2}$, ou $\mathrm{Pb}_{5}\left(\mathrm{PO}_{4}\right)_{3} \mathrm{OH}$, dependendo do $\mathrm{pH}$. Em solos calcáreos, a forma $\mathrm{PbCO}_{3}$ pode predominar.

Elliott et al. (1986) propuseram que em condições ácidas, o fenômeno da adsorção é mais importante no controle da biodisponibilidade de metais, enquanto reações de precipitação e complexação tem maịor relevância em condições neutras e alcalinas. $\mathrm{O}$ aumento do $\mathrm{pH}$, portanto, favorece a adsorção por meio do incremento das espécies hidrolisadas, pela menor competição com íons $\mathrm{Al}^{3+} \mathrm{e}^{+}$pelos sítios de troca e pelo aumento da CTC do solo. Em geral o $\mathrm{pH}$ deve exceder 6,5, para que a mobilidade e toxicidade desses elementos no solo seja minimizada (Ellis \& Knezek, 1977).

De acordo com Guidi et al. (1990), plantas cultivadas em solo com $\mathrm{pH}$ próximo à neutralidade absorvem menos metais pesados que em solos ácidos. Sob condições alcalinas, há formação de precipitados de carbonatos e hidróxidos metálicos e, além disso, ocorre o aumento da CTC do solo, resultando em menor adsorção de cátions metálicos (Hue et al., 1988).

O efeito da calagem na disponibilidade de metais pesados foi verificado por Hooda \& Alloway (1996), em solos tratados com biossólido e cultivados com trigo, cenoura e espinafre. Os resultados indicaram que a manutenção do pH a 7,0 é mais importante que a $\mathrm{pH} 6,5$, pois uma pequena variação deste atributo pode disponibilizar os metais. Com isto, podemos inferir que, o valor de $\mathrm{pH}$ de solos que receberam aplicação de resíduos contendo metais pesados devem ser monitorados constantemente. 


\subsubsection{Matéria orgånica do solo e disponibilidade de chumbo}

A matéria orgânica do solo tem sido extensivamente relacionada com a adsorção de metais, devido à expressiva participação na magnitude da capacidade de troca de cátions e, principalmente, pela tendência dos metais formarem complexos estáveis com ligantes orgânicos (Alleoni, 2000). Entretanto, com a decomposição dos colóides orgânicos que complexam os metais, o efeito protetor da matéria orgânica desaparece (Melo et al., 1997).

A reação do cátion metálico organicamente complexado, provavelmente, deve ser diferente em relação ao inorganicamente complexado, pois a complexação pelas substâncias húmicas neutralizam a carga positiva do cátion metálico (Singh \& Pandeya, 1998). Kabata-Pendias \& Pendias (1984) atribuíram a baixa biodisponibilidade do $\mathrm{Pb}$. e a acumulação nos horizontes superficiais, à elevada capacidade de complexação do $\mathrm{Pb}$ pela matéria orgânica. Resultados semelhantes foram obtidos por Abreu et al. (1998).

Os estudos de Canãdas et al. (1986) em solos com baixo teor de matéria orgânica, contaminados com $\mathrm{Pb}$ e não, mostraram que o metal pouco se relacionou com a fração orgânica, estando ligado principalmente a óxidos de Fe e Mn. Ao contrário desses resultados, Xian (1989) observou a fundamental relevância da matéria orgânica do solo na retenção do $\mathrm{Pb}$ em áreas contaminadas.

O fracionamento da matéria otgânica do solo é essencial para o entendimento de uma relação com a retenção do $\mathrm{Pb}$. A fração ácido húmico do solo influencia a disponibilidade de cátions presentes na solução, por meio de sua capacidade adsortiva, dependente da concentração hidrogeniônica do meio. Essa fração tem maior afinidade por $\mathrm{Pb}$ e $\mathrm{Cu}$, comparativamente a cádmio e zinco, e também é importante na formação de complexos mais estáveis com aqueles elementos. Entretanto, em valores de pH acima de 6,5, há solubilização dos ácidos 
húmicos e, como conseqüência, a capacidade de retenção de íons $\mathrm{Pb}^{2+}, \mathrm{Cu}^{2+}, \mathrm{Zn}^{2+} \mathrm{e}$ $\mathrm{Cd}^{2+}$ diminui gradativamente com o aumento de $\mathrm{pH}$ do meio (Siqueira, 1987).

Costa (1991) concluiu que $\mathrm{Fe}, \mathrm{Al}$ e $\mathrm{Pb}$ apresentam adsorção máxima em ácidos húmicos a $\mathrm{pH}$ 6,5. A seqüência de afinidade de metais por ácidos húmicos é: $\mathrm{Cu}>\mathrm{Pb}>\mathrm{Cd}>\mathrm{Zn}$ e por ácidos fúlvicos: $\mathrm{Cu}>\mathrm{Pb}>\mathrm{Zn}>\mathrm{Cd}$ (Elliott et al., 1986).

A influência da calagem e de concentrações de metais num Latossolo Vermelho-amarelo foi estudada por Gomes (1996). $\mathrm{O}$ autor concluiu que o $\mathrm{Pb}$ foi o elemento que apresentou maior afinidade pela forma orgânica, associando-se a compostos orgânicos mais recalcitrantes. A influência das doses mostrou o maior incremento de $\mathrm{Pb}$ nas substâncias húmicas do horizonte $\mathrm{A}$, e na forma residual no horizonte $\mathrm{B}$.

Os estudos de Amaral Sobrinho (1997) com o calcário-resíduo de Paracatú, revelaram pouca influência da matéria orgânica na retenção do $\mathrm{Pb}$ adicionado ao solo via esse resíduo. Entretanto, o autor observou a relação entre o metal e a elevação do $\mathrm{pH}$ proporcionada pela adição do resíduo. Com o aumento do pH não foi observada a precipitação do $\mathrm{Pb}$, o que foi discutido como problema metodológico relacionado aos extratores empregados.

McGrath \& Cegarra (1992) realizaram extração seqüencial em amostras de solo, na qual a última aplicação de biossólido havia sido feita a 20 anos e $70 \%$ da matéria orgânica adicionada já havia sido decomposta. Os resultados mostraram que as concentrações dos metais $\mathrm{Cd}, \mathrm{Cr}, \mathrm{Ni}, \mathrm{Pb}$ e $\mathrm{Zn}$ permaneceram relativamente constantes no solo, sendo que apenas o $\mathrm{Ni}$ apresentou redução em sua disponibilidade. As mesmas conclusões foram feitas por Brown et al. (1998) para o Cd, numa área onde a aplicação de biossólido foi cessada há 13 anos, usando alface como planta teste. 


\subsubsection{Absorção radicular de chumbo}

O processo de absorção de um nutriente pela planta pode ser com ou sem gasto de energia, sendo convencionado de ativo ou passivo, respectivamente (Malavolta, 1980).

A absorção do $\mathrm{Pb}$, na maioria das espécies vegetais, é um processo passivo, que pode sofrer alteração com a temperatura (Kabata-Pendias \& Pendias, 1985), além de apresentar efeito competitivo com o $\mathrm{Ca}^{2+}$ (Malavolta, 1980). Após absorvido, $\mathrm{O} \mathrm{Pb}$ acumula-se nas paredes celulares, o que deve contribuir para a diminuição do efeito tóxico na planta. A redução no acúmulo de metais pesados em arroz e tomate com a elevação do teor de cálcio da solução do solo foi observada por Hosono et al. (1979), mostrando a influência da competição iônica entre o íon $\mathrm{Ca}^{2+} \mathrm{e}$ o $\mathrm{Pb}^{2+}$.

De acordo com Guidi et al. (1990), a absorção de metais pesados é menor em solos com $\mathrm{pH}$ próximo a 7 em relação a solos mais ácidos. Já sob condições alcalinas, há formação de precipitados de carbonatos e hidróxidos metálicos.

A concentração dos metais varia nos tecidos da planta. Segundo King \& Hajjar (1990), as concentrações de $\mathrm{Zn}$ e de Cd diminuíram nas folhas mais novas na planta de fumo (Nicotiana tabacum L.). Em geral, os grãos contêm uma concentração menor de metais que as partes vegetativas da planta. Existem algumas supostas explicações para a baixa translocação do $\mathrm{Pb}$ na planta, como o antagonismo com o Zn nos vasos das raizes e a precipitação com fosfatos nos vasos xilemáticos (Mortvedt, 1985; Artega, 1996).

Davis et al. (1988) estudaram a fitotoxicidade de metais pesados para cevada (Hordeum vulgare L.) e observaram $35 \mu \mathrm{g}$ de $\mathrm{Pb} \mathrm{g}^{-1}$ de matéria seca. De acordo 
com Kabata-Pendias \& Pendias (1984), o valor normal para $\mathrm{Pb}$ em material vegetal está entre 5 e $10 \mu g g^{1}$, e valores críticos estão entre 30 e $300 \mu g g^{1}$.

\subsubsection{Exsudados de raízes e absorção radicular de chumbo}

Estudos recentes demonstraram que os exsudados das raizes tem um importante papel na solubilização dos metais no solo (Krishnamurti et al., 1997; Mench \& Martin, 1991). Metais quelados na solução do solo, ao entrarem em contato com a rizosfera, podem ser liberados, devido ao $\mathrm{pH}$ nessa região ser mais baixo que o da solução do solo (Bowen \& Rovira, 1991).

Segundo Berton (2000), as raizes das plantas liberam enormes quantidades de compostos orgânicos que são a principal fonte de energia para os microrganismos que habitam a rizosfera. De acordo com Godo \& Reisenauer (1980) e Merckx et al. (1986), como a concentração de metais na solução do solo é muito baixa, a solubilização dos metais presentes na fase sólida por exsudados de raízes não deve ser desprezada. Manch \& Martin (1991), observaram que os exsudados de raízes coletados de três espécies vegetais (Nicotiana tabacum, L., Nicotiana rústica L. e Zea mays $\mathrm{L}$.) aumentaram a solubilidade do $\mathrm{Mn}$ e do $\mathrm{Cu}$, e que as quantidades de $\mathrm{Cd}$ extraídas pelos exsudados, foram similares às quantidades absorvidas desse elemento por essas três espécies, quando cultivadas no solo. Hinsinger (1999), cita que as raizes de gramíneas podem liberar fitosideróforos que liberam o Fe e outros metais como o Cd, Cu e Zn, complexados, aumentando a eficiência de absorção.

Segundo Merckx et al. (1986), os ácidos orgânicos de baixo peso molecular, como o acético, cítrico, oxálico, fumárico e succínico, geralmente presentes nos exsudados de raizes, são os mais eficientes na solubilização dos metais presentes no solo. 
De acordo com Berton (2000), assumindo-se que a solubilização pelos exsudados de raizes é fundamental para a absorção de metais pela planta, em se identificando a composição química desses exsudados para plantas cultivadas comercialmente, poder-se-ia estimar, com precisão, as quantidades biodisponíveis totais dos metais presentes no solo. Como a composição química dos exsudados de raizes é específica para cada espécie e difere na sua habilidade em solubilizar metais, torna-se oportuno a caracterização da composição química dos exsudados para cada espécie vegetal.

Matiazzo-Prezotto et al. (1998) realizaram uma revisão sobre a eficiência dos métodos de avaliação de extratores inorgânicos, orgânicos e de um modelo de especiação iônica da solução do solo. Os autores concluíram que ainda não existe extrator com boa correlação entre as quantidades fitodisponíveis para todos os metais pesados existentes no lodo de esgoto e que há necessidade de se padronizar os métodos de análise a fim de maximizar os resultados obtidos em condições de solos ácidos, ricos em óxidos de ferro, alumínio e manganês.

Segundo King (1996), não tem sido obtida boa correlação entre os metais extraídos pelos extratores inotgânicos, geralmente utilizados para avaliação dos níveis de fertilidade do solo (EDTA, DTPA, Mehlich 3), com a concentração de metais na planta em solos com altos teores desses elementos. Isso se deve ao fato de que esses extratores não foram desenvolvidos para essa finalidade.

Berton et al. (1997) obtiveram alta correlação $\left(R^{2}>0,95\right)$ entre as quantidades de $\mathrm{Zn}$ e de Cu extraídas pelo DTPA e aquelas acumuladas na parte aérea do milho, em três solos do Estado de São Paulo, que receberam adição de até 100 t ha ${ }^{-1}$ de biossólido (material seco), com ou sem $\mathrm{CaCO}_{3}$ para elevação do $\mathrm{pH}$ para 6,0. Entretanto, os coeficientes desses extratores dependem do tipo de solo e da espécie vegetal empregada. A incorporação de algumas características do solo, como o $\mathrm{pH}$, nas análises múltiplas de regressão tem aumentado o coeficiente de determinação para esses extratores. 


\subsection{Acidez do solo}

Como a maioria dos solos sob clima tropical, com alto grau de intemperismo, os solos brasileiros apresentam de média a alta acidez, com $\mathrm{pH}$ em água normalmente menor que 5,5 (Veloso, 1992). Níveis tóxicos de alumínio e manganês também podem ser observados, além de deficiência de cálcio, magnésio e fósforo.

Nestes solos, ocorre predominância de cargas variáveis, dependentes dentre outros fatores, do $\mathrm{pH}$, o que pode determinar, sob condições de acidez elevada, uma capacidade de troca catiônica (CTC) baixa (Malavolta \& Kliemann, 1985).

\subsubsection{Origem da acidez do solo}

Os solos podem ser naturalmente ácidos em razão da pobreza do material de origem em $\mathrm{Ca}, \mathrm{Mg}, \mathrm{K}$ e $\mathrm{Na}$, ou através de processos de formação ou de manejo de solos que levam à perda destas bases e, portanto, à acidificação. $O$ processo de acidificação consiste na remoção desses cátions para camadas mais profundas do perfil do solo, fora do alcance das raízes. Malavolta \& Kliemann (1985) atribuiu a acidificação à: percolação de cátions básicos e conseqüente acúmulo de $\mathrm{H}_{3} \mathrm{O}^{+}$; a decomposição dos minerais de argila e o surgimento de Al trocável; oxidação microbiana do nitrogênio amoniacal; exsudação de ions $\mathrm{H}^{+}$pelas raízes das plantas para a manutenção do equilíbrio eletrostático do sistema após a absorção de cátions e dissociação de radicais carboxílicos e fenólicos da matéria orgânica. 
Segundo Melo (1985), o aluminio surge no solo na forma trocável e na solução, devido ao processo de dissolução de hidróxido de alumínio amorfo e cristalino em meio ácido. Com a formação dos monômeros de alumínio, este elemento torna-se responsável por grande parte da acidez do solo pois é um anfólito e quando em solução, na forma de íon hexahidratado, apresenta um comportamento ácido, expresso, segundo a teoria de Bronsted-Lowrys, pelos seguintes equilibrios de transferência de prótons:

\begin{tabular}{|c|c|c|}
\hline $\left.\mathrm{Al}\left(\mathrm{H}_{2} \mathrm{O}\right)_{6}\right]^{3+}+\mathrm{H}_{2} \mathrm{O}$ & $\Leftrightarrow$ & $\mathrm{H}_{3} \mathrm{O}^{+}+\left[\mathrm{Al}(\mathrm{OH})\left(\mathrm{H}_{2} \mathrm{O}\right)_{5}\right]^{2-}$ \\
\hline base & & base \\
\hline$\underset{\text { ácido }}{\left[\mathrm{Al}(\mathrm{OH})\left(\mathrm{H}_{2} 0\right)_{5}\right]^{2+}}+\underset{\mathrm{H}_{2} \mathrm{O}}{\mathrm{H}^{2}}$ & $\Leftrightarrow$ & 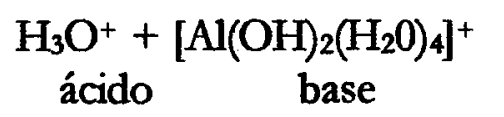 \\
\hline$\underset{\text { ácido }}{\left[\mathrm{Al}(\mathrm{OH})\left(\mathrm{H}_{2} \mathrm{O}\right)_{4}\right]^{+}}+\underset{\mathrm{H}_{2} \mathrm{O}}{\mathrm{H}^{2}}$ & $\Leftarrow$ & $\begin{array}{c}\mathrm{H}_{3} \mathrm{O}^{+}+\mathrm{Al}(\mathrm{OH})_{3} 3 \mathrm{H}_{2} \mathrm{O} \\
\text { ácido } \quad \text { base }\end{array}$ \\
\hline
\end{tabular}

2.3.2 Efeito da matéria orgânica na acidez do solo

A técnica mais utilizada na agricultura para neutralizar $\mathrm{H}^{+}$e $\mathrm{Al}^{3+}$ em solos ácidos é a aplicação de calcário, que são produtos de baixo custo, fácil aplicação e fonte de Ca e $\mathrm{Mg}$ para as plantas. Outra alternativa para a correção da acidez e neutralização de toxidez de $\mathrm{Al}$ é a aplicação de resíduos orgânicos no solo, na forma de estercos de animais, compostos e resíduos vegetais, que apresentam um efeito semelhante ao da calagem (Cassiolato et al., 1999; Franchini et al., 1999a; Hoyt \& Turner, 1975; Hue \& Amien, 1989; Miyazawa et al., 1993).

A redução de toxidez de Al pela aplicação de calcátio ocorre pela precipitação de $\mathrm{Al}^{3+}$ em forma de hidróxido, $\mathrm{Al}(\mathrm{OH})_{3}$. Os resíduos orgânicos de 
vegetais e de animais também reduzem a toxidez de $\mathrm{Al}$ (Miyazawa et al., 2000). Os resíduos vegetais reduzem a toxidez de $\mathrm{Al}$ por duas reações químicas distintas, a primeira por precipitação do $\mathrm{Al}^{3+}$ e outra por complexação do $\mathrm{Al}$ com ácidos orgânicos.

Às vezes, a elevação de $\mathrm{pH}$ pela incorporação ao solo de materiais orgânicos tem efeito temporário, retornando aos valores iniciais algumas semanas após a aplicação (Hensler et al., 1970; Hoyt \& Tumer, 1975; Hoyt, 1977; Epstein et al., 1976 e Franchini et al., 1999b). Nesses casos, atribui-se a elevação do pH à liberação de amônia durante a decomposição microbiana dos resíduos orgânicos. Assim, a elevação do $\mathrm{pH}$ tem duração efêmera e sua amplitude varia com as taxas de sua liberação (Epstein et al., 1976). Pode ocorrer também, quando da adição de estercos ao solo, a elevação do $\mathrm{pH}$, e esta persistir por vários anos (Lund \& Doss, 1980 e Nuemberg \& Stammel, 1989). Lund \& Doss (1980) atribuem esse efeito à presença de óxidos de cálcio e magnésio no resíduo, que lhe confere certo poder de neutralização.

Segundo Miyazawa et al. (2000), o caráter anfótero das substâncias orgânicas dos resíduos vegetais faz com que o $\mathrm{pH}$ aumente em solos ácidos e diminua em solos alcalinos, sempre tendendo para valores próximos do $\mathrm{pK}_{\mathrm{a}}$ de cada ácido orgânico. Os valores de $\mathbf{p k}_{\mathbf{a}}$ dos compostos orgânicos dos resíduos vegetais geralmente variam em torno de 4,5 a 6,5.

Em solos que receberam aplicação de vinhaça, Cambium \& Cordeiro (1986) e Camargo et al. (1987) explicam que a elevação no $\mathrm{pH}$ é resultante da introdução de cátions básicos ao sistema, tendo em vista a alta correlação entre o $\mathrm{pH}$ e a saturação por bases encontradas por estes autores. Reis \& Rodella (1998) atribuíram a elevação no $\mathrm{pH}$ ao fato de que cerca de $90 \%$ do carbono da vinhaça ser solúvel e assim participar de processos que não ocorrem com as formas sólidas de carbono. Os efeitos da aplicação de vinhaça sobre o $\mathrm{pH}$ do solo também foi observado por Prata (1998). 
King \& Morris (1972), utilizando altas doses de lodo de esgoto, constataram decréscimo do valor de $\mathrm{pH}$, que pode ser atribuído à nitrificação do nitrogênio amoniacal e orgânico e à oxidação de sulfetos.

\subsubsection{Efeito do pH no teor de $\mathrm{Al}$ trocável}

As determinações de $\mathrm{Al}$ trocável, é um índice técnico, usualmente utilizado. Diversos trabalhos têm mostrado que os efeitos prejudiciais da acidez se devem a atividade química do Al na solução que está em equilíbrio com a fração trocável. Porém, o teor de $\mathrm{Al}^{3+}$ trocável no solo pode ser um parâmetro para avaliar a sua toxicidade para as plantas.

A solubilidade do alumínio e, consequentemente, sua toxicidade para as plantas são afetadas por vários fatores, tais como o $\mathrm{pH}$ do solo, conteúdo de matéria orgânica, características mineralógicas da fração argila e a concentração de outros cátions na solução do solo (Foy, 1974, 1992). Furlani e Berton (1992) relataram a dificuldade em se definir uma concentração crítica de Al tóxico. Segundo os autores, os fatores do meio de crescimento das plantas, solução nutritiva ou solo, tais como: $\mathrm{pH}$, força iônica da solução, espécie vegetal, presença de quelatos ligantes e outros, podem atuat na modificação da resposta da planta ao alumínio.

Existem três faixas definidas de $\mathrm{pH}$ em relação à estabilidade do alumínio em solução aquosa. Acima de $\mathrm{pH} 7,5$, a solubilidade aumenta significativamente, aparecendo o alumínio na forma aniônica $\left[\mathrm{Al}(\mathrm{OH})^{-4}\right]$. Esta condição de $\mathrm{pH}$ não ocorre comumente no Brasil, apenas em alguns casos de solos sob clima átido a semi-árido, normalmente encontrado na região nordeste. Na faixa entre 7,5 e 5,2, há pouca ou quase nenhuma ocorrência de alumínio solúvel, corresponde à faixa de precipitação como $\mathrm{Al}(\mathrm{OH})_{3} .3 \mathrm{H}_{2} \mathrm{O}$. Já na faixa de $\mathrm{pH}$ entre 4 e 5 ; a sua solubilidade 
novamente aumenta significativamente. Esta última tem sido motivos de grandes perdas de produtividade em solos sob clima tropical, principalmente cerrado, em que a acidificação do solo é comum e constante.

Normalmente, a toxicidade ao alumínio não está presente em solos que apresentam $\mathrm{pH}$ superior a 5,5. A faixa de $\mathrm{pH}$ de maior importância do ponto de vista da toxicidade em solos ácidos é de 4,0 a 5,5. A toxicidade de alumínio é especificamente severa em solos com $\mathrm{pH}$ abaixo de 5,0, mas pode ocorrer em solos com valor de $\mathrm{pH}$ até 5,5 (Mesquita Filho \& Souza, 1986).

Gonçalves et al. (2000) observaram que com o aumento de doses de biossólidos aplicados ao solo, houve uma redução nos teores de $\mathrm{Al}, \mathrm{Fe}$ e $\mathrm{Mn}$, sem que houvesse alteração significativa do $\mathrm{pH}$, pois o mesmo foi elevado em apenas 0,2 unidades. Mostrando assim que apenas a adição de matéria orgânica via biossólido, reduziu as espécies quimicas tóxicas.

\subsection{Cálcio e magnésio}

Os silicatos são os principais minerais primários que contêm $\mathrm{Ca}$, sendo que o mais importante é a anortita $\left(\mathrm{CaAl}_{2} \mathrm{Si}_{2} \mathrm{O}_{8}\right)$. O carbonato de cálcio $\left(\mathrm{CaCO}_{3}\right)$, nas regiões áridas e semi-áridas e em solos jovens de regiões úmidas, constitui-se na mais importante fonte de cálcio.

Para o magnésio, os silicatos constituídos deste elemento são: homblenda, augita, olivina, talco, serpentina, clorita e biotita. Entretanto, de acordo com Tisdale et al (1985), a dolomita $\left(\mathrm{CaCO}_{3} . \mathrm{MgCO}_{3}\right)$ é a principal fonte de $\mathrm{Mg}$. A dolomita, embora menos abundante, pode aparecer associada ao carbonato de cálcio. $\mathrm{Na}$ maioria dos solos cultivados, a principal fonte de $\mathrm{Ca}$ e $\mathrm{Mg}$, sem dúvida, é o calcário dolomítico ou magnesiano. 
O cálcio e o magnésio disponíveis para as plantas estão nas suas formas iônicas, ou seja, $\mathrm{Ca}^{2+}$ e $\mathrm{Mg}^{2+}$, dissolvidos na solução do solo, que estão em equilíbrio com o Ca e o Mg trocáveis. Havendo diminuição na concentração destes elementos na solução do solo, há reposição destes por aqueles que se encontravam adsorvidos aos colóides.

O fator de maior importância na energia de atração colóide-cátion, é a valência de suas cargas, em segundo lugar em grau de importância, é o tamanho dos ions hidratados, sendo que os menores são retidos com maior energia. Assim, o cálcio trocável encontra-se mais fortemente retido aos colóides do solo que o magnésio trocável, por ter maior grau de hidratação e apresentar menor diâmetro, o que the proporciona maior força de retenção que o magnésio (Raij, 1991).

Alguns autores relataram existir uma competição iônica entre o $\mathrm{K}^{+}$e o $\mathrm{Mg}^{2+}$, tendo como principal conseqüência redução na absorção do $\mathrm{Mg}^{2+}$ (Malavolta, 1976; Mello et al., 1989).

Os principais fatores do solo que afetam a disponibilidade de $\mathrm{Ca}$ e $\mathrm{Mg}$ para as plantas são os seguintes: quantidade de cálcio e magnésio trocáveis presentes, grau de saturação do complexo de troca, tipo de colóide do solo, natureza dos íons complementares adsorvidos no complexo de troca (Tisdale et al. 1985; Mello et al., 1989).

\subsubsection{Efeito do $\mathrm{pH}$ na disponibilidade de $\mathrm{Ca}$ e $\mathrm{Mg}$}

$\mathrm{O}$ pH controla a solubilidade dos nutrientes do solo exercendo considerável influência sobre a absorção destes pelas plantas. Segundo Malavolta (1976), o Ca e o $\mathrm{Mg}$ são aproveitados com maior intensidade nos solos com $\mathrm{pH}$ 
entre 6,5 e 8,5. Solos muito ácidos são pobres em $\mathrm{Ca}$ e $\mathrm{Mg}$ e nos solos muito alcalinos eles se encontram em grande parte insolubilizados.

$\mathrm{O} \mathrm{Ca}$ e o $\mathrm{Mg}$ podem ser removidos do solo por lixiviação, erosão e remoção pelas colheitas. As perdas por erosão dependem da quantidade de chuva, do teor de $\mathrm{Ca}$ e de $\mathrm{Mg}$ no solo e da textura do solo. A aplicação de alguns fertilizantes nitrogenados e sulfatados, acelera as perdas de cálcio. Os sais nítricos e sulfatos deslocam o Ca trocável que é perdido na água de percolação, sendo acompanhado por um ânion móvel para manter a neutralidade elétrica.

\subsubsection{Absorção radicular de Ca e $\mathrm{Mg}$}

As plantas absorvem cálcio e magnésio predominantemente da solução do solo por fluxo de massa, mas podem absorver diretamente do solo através da interceptação radicular, em virtude de encontrarem-se em teores altos na solução do solo. Normalmente, as quantidades de $\mathrm{Ca}$ e $\mathrm{Mg}$ no solo são suficientes para suprir a necessidade das plantas, exceto em condições de solos ácidos não calcariados e altamente lixiviados (Tisdale et al: 1985; Raij, 1987).

A absorção de cálcio e de magnésio pelas plantas se dá na forma iônica $\mathrm{Ca}^{2+}$ e $\mathrm{Mg}^{2+}$. Segundo Mengel \& Kirkby (1987), a capacidade de absorção de cálcio pelas plantas é limitada porque este é absorvido somente pelas pontas das raízes novas que ainda não possuem a parede celular da endoderme suberizada.

De acordo com Huang (1992), o Al pode inibir a absorção de Ca pelo bloqueamento dos canais de $\mathrm{Ca}$ na membrana plasmática, enquanto Rengel \& Robinson (1989) demonstraram que o Al impede a absorção de $\mathrm{Mg}$ por bloquear os sítios de ligação desse nutriente às proteínas transportadoras. 


\subsubsection{Matéria orgânica como fonte de $\mathrm{Ca}$ e $\mathrm{Mg}$}

O teor de cálcio e magnésio presente na matéria orgânica varia de acordo com a sua origem, condições climáticas, práticas culturais etc.. $\mathrm{O} \mathrm{Ca}$ presente pode estar na forma de compostos orgânicos como quelatos ou complexos ou adsorvidos à matéria orgânica. Uma proporção relativamente grande de $\mathrm{Mg}$ dos restos vegetais incorporados, que darão origem ao húmus, está presente nạ clorofila (Malavolta; 1976; Mello et al., 1989). A matéria orgânica não é vista como uma importante fonte de $\mathrm{Ca}$ e $\mathrm{Mg}$, pois, de um modo geral, os teores destes elementos estão em menores proporções que outros, como N, P, S e B. Sendo assim, dá-se maior importância a entrada de $N, P, S$ e $B$ no solo via matéria orgânica. Porém, alguns compostos podem ter teores relativamente altos de $\mathrm{Ca}$ e, principalmente, $\mathrm{Mg}$.

Gonçalves et al. (2000), trabalhando com biossólidos, revelaram que à medida que se elevaram as doses aplicadas do resíduo, há uma nítida elevação das concentrações de $\mathrm{Ca}$ e $\mathrm{Mg}$. Independente disto, o pH elevou-se apenas 0,2 unidades. Essas alterações na disponibilidade de nutrientes refletiram em variações na composição química do tecido foliar, tendo como resultado o aumento no teor de $\mathrm{Ca}$ e diminuição nos teores de Fe e Mn. Eles concluíram ainda que, se a aplicação do

resíduo tivesse sido incorporada ao solo, essas alterações seriam maiores, por ter uma maior solubilização e reação do biossólido no solo. 


\section{MATERIAL E MÉTCDOS}

O presente estudo foi conduzido no Departamento de Ciências Exatas, área de Química Ambiental da Escola Superior de Agricultura "Luiz de Queiroz" ESALQ, da Universidade de São Paulo, no município de Piracicaba - SP. Doses do resíduo-corretivo, calcário de Paracatú, foram associadas a doses de esterco bovino, escolhido como fonte de matéria orgânica, e incubados por 90 dias.

O delineamento experimental constou de 15 tratamentos, com 3 repetições, compreendendo 45 parcelas experimentais. Os tratamentos distribuidos em esquema fatorial completo $5 \times 3$, correspondem a 5 doses do resíduo-corretivo correspondentes a $0,2,4,8$ e $12 \mathrm{Mg}^{h^{-1}}$ e a 3 doses de esterco bovino correspondentes a 0,13 e $26 \mathrm{Mg} \mathrm{ha}$. Os resultados foram analisados por análise de regressão, teste $F$, ao nível de $5 \%$.

\subsection{Caracterização do material utilizado}

\subsubsection{Solo}

Utilizaram-se amostras da camada 0-0,20 m de um Cambissolo Háplico Alumínico, coletadas na região de Mombuca - SP em área cultivada com cana de açúcar. As amostras foram secas ao ar, peneiradas e passadas em malha de $2 \mathrm{~mm}$ de abertura. 
As amostras de solo apresentaram as seguintes características granulométricas, determinadas através do método do densímetro: areia $=220 \mathrm{~g} \mathrm{~kg}^{-1}$; silte $=310 \mathrm{~g} \mathrm{ka}^{-1} \mathrm{e}$ argila $=470 \mathrm{~g} \mathrm{~kg}^{-1}$. As características químicas, determinadas segundo Raij et al., 1987, são: $\mathrm{pH}$ em $\mathrm{CaCl}_{2}=4,1$; Matéria orgânica total $=20 \mathrm{~g} \mathrm{dm}$ 3; $\mathrm{P}=4 \mathrm{mg} \mathrm{dm}^{-3} ; \mathrm{K}=1,9 \mathrm{mmol}_{\mathrm{c}} \mathrm{dm}^{-3} ; \mathrm{Ca}=25 \mathrm{mmol}_{\mathrm{c}} \mathrm{dm}^{-3} ; \mathrm{Mg}=9 \mathrm{mmol}_{\mathrm{c}} \mathrm{dm}^{-3} ; \mathrm{Al}$ $=31 \mathrm{mmol}_{\mathrm{c}} \mathrm{dm}^{-3} ; \mathrm{H}+\mathrm{Al}=108 \mathrm{mmol}_{\mathrm{c}} \mathrm{dm}^{-3} ; \mathrm{SB}=35,9 \mathrm{mmol}_{\mathrm{c}} \mathrm{dm}^{-3} ; \mathrm{CTC}=143,9$ $\mathrm{mmol}_{\mathrm{c}} \mathrm{dm}^{-3} ; \mathrm{V} \%=24,9 ; \mathrm{m}=46,3 \%$ e $\mathrm{Pb}=16 \mathrm{mg} \mathrm{dm} \mathrm{d}^{-3}$. O chumbo foi determinado segundo Amacher (1996).

\subsubsection{Material orgânico}

A fonte de matéria orgânica utilizada foi esterco bovino seco e moído. Esse material foi analisado segundo Brasil (1988): matéria seca a $65^{\circ} \mathrm{C}$, matéria orgânica total e $\mathrm{o}$ pH em água. $\mathrm{O}$ nitrogênio foi determinado pelo método de Kjeldahl, através de digestão da amostra com $\mathrm{H}_{2} \mathrm{SO}_{4}$, seguida de destilação em meio alcalino. As determinações de carbono foram feitas por volumetria de oxi-redução, empregando dicromato de potássio em meio ácido, a quente (Rodella \& Alcarde, 1994). O teor total dos demais elementos foram determinados em extrato nítricoperclórico de acordo com metodologia descrita em Eaton et al., 1995.

As características, com base na matéria seca em estufa à $65^{\circ} \mathrm{C}$ são: $\mathrm{pH}$ (em $\mathrm{H}_{2} \mathrm{O}$, relação1:2,5) $=7,5$; Umidade $\left(65^{\circ} \mathrm{C}\right)=88 \mathrm{~g} \mathrm{~kg}^{-1}$; Matéria orgânica total = $901,2 \mathrm{~g} \mathrm{~kg}^{1} ; \mathrm{C}$ orgânico total $378,3 \mathrm{~g} \mathrm{~kg}^{1} ; \mathrm{N}$ total $=18,1 \mathrm{~g} \mathrm{~kg}^{-1} ; \mathrm{K}=16,4 \mathrm{~g} \mathrm{~kg}^{-1} ; \mathrm{Ca}$ $=12,6 \mathrm{~g} \mathrm{~kg}^{-1} ; \mathrm{Mg}=2,3 \mathrm{~g} \mathrm{~kg}^{-1} ; \mathrm{P}$ total $=7,4 \mathrm{~g} \mathrm{~kg}^{-1}$. A relação $\mathrm{C} / \mathrm{N}$ desse material foi de 20,9 e o teor de $\mathrm{Pb}$ total foi de $13 \mathrm{mg} \mathrm{kg}^{-1}$. 


\subsubsection{Resíduo-corretivo}

O resíduo-corretivo de solo, conhecido comercialmente como "calcário de Paracatú", produzido no município de Paracatú-MG, é subproduto da extração do minério de zinco. As características do resíduo-corretivo de Paracatú foram realizadas segundo Brasil (1988) e Page (1982). A umidade desse resíduo era de $3 \mathrm{~g}$ $\mathrm{kg}^{-1}$ e suas características granulométricas foram: peneira 10 (ABNT) $=99,6 \%$; peneira $20(A B N T)=92,3 \%$ e peneira $50(A B N T)=82,7 ;(2)$ umidade $=0,3 \%$. As características determinadas no resíduo-corretivo, como corretivo de solos, foram: $\mathrm{PN}\left(\mathrm{E}_{\mathrm{CaCO} 3}\right)$ determinado $=84,80 \% ; \mathrm{PN}\left(\mathrm{E}_{\mathrm{CaCO} 3}\right)$ calculado $=94,52 \% ; \mathrm{CaO}=30,00$ $\% ; \mathrm{MgO}=16,46 \% ; \mathrm{CaO}+\mathrm{MgO}=45,30 \%$ e PRNT $=76,20 \%$. Observando-se as características físicas e como corretivo de solos do resíduo, pode-se considerá-lo como um corretivo da acidez de solos e como fonte de cálcio e magnésio. Caso este fosse um produto da moagem de rocha calcária, ou seja, calcário, poder-se-ia classificar como calcário magnesiano, faixa $\mathrm{C}$, de acordo com legislação vigente.

Para a determinação dos teores totais de $\mathrm{Pb}$ e $\mathrm{Cd}$, o residuo-corretivo foi moído, em almofariz de ágata, a pó fino. Posteriormente, digeriu-se $1,000 \mathrm{~g} \mathrm{da}$ amostra em ácido nítrico concentrado, transferiram-se os extratos para balões volumétricos de $50 \mathrm{~mL}$. Realizaram-se as determinações de $\mathrm{Pb}$ e $\mathrm{Cd}$ por espectroscopia de absorção atômica em chama (FAAS). Os teores de chumbo e cádmio presentes nas amostras foram de 4.120 e $90 \mathrm{mg} \mathrm{kg}^{-1}$, respectivamente. 


\subsection{Experimento de incubação}

Incubaram-se $500 \mathrm{~g}$ da amostra do solo em estudo durante 90 dias com os tratamentos contendo esterco bovino e o resíduo-corretivo de Paracatú - MG, mantendo-se a umidade a $70 \%$ da capacidade de saturação. A base de cálculo utilizada para adição do resíduo e da fonte de matéria orgânica aos vasos foi a seguinte:

$$
\begin{aligned}
& 1 \mathrm{ha}=10.000 \mathrm{~m}^{2} ; \\
& \text { Profundidade }=0,20 \mathrm{~m} ; \\
& \text { Densidade do solo }=1,2 \mathrm{~g} \mathrm{~cm}^{-3} .
\end{aligned}
$$

Desse modo, para os tratamentos $0,2,4,8 \mathrm{e} 12 \mathrm{t} \mathrm{ha}^{-1}$ foram adicionados, respectivamente $0,0,385,0,769,1,538$ e $2,307 \mathrm{~g}$ do resíduo-corretivo, com relação à fonte de matéria orgânica, para os tratamentos 0,13 e $26 \mathrm{t} \mathrm{ha}^{-1}$ foram adicionados, respectivamente, $0,2,6$ e 5,2 $\mathrm{g}$ de esterco bovino. Compreendendo assim, um esquema fatorial completo $5 \times 3$, com 3 repetições.

\subsection{Análises}

Após o período de 90 dias de incubação, o solo dos tratamentos foram secos ao ar e homogeneizado e amostrado para as determinações de $\mathrm{pH}\left(\mathrm{H}_{2} \mathrm{O}\right)$, $\mathrm{Ca}^{2+}, \mathrm{Mg}^{2+}, \mathrm{Al}^{3+}, \mathrm{Pb}^{2+}$ total e $\mathrm{Pb}^{2+}$ trocável. 


\subsubsection{Cálcio, magnésio, alumínio e pH}

A extração de $\mathrm{Ca}^{2+}, \mathrm{Mg}^{2+}$ e $\mathrm{Al}^{3+}$ foi feita com solução de $\mathrm{KCl} 1 \mathrm{~mol} \mathrm{~L}{ }^{-1}$. A concentração de $\mathrm{Ca}^{2+}$ e $\mathrm{Mg}^{2+}$ foi obtida por espectrofotometria de absorção atômica em chama (FAAS), e de $\mathrm{Al}^{3+}$ por alcalimetria. $\mathrm{O} \mathrm{pH}\left(\mathrm{H}_{2} \mathrm{O}\right)$ foi determinado com a relação solo/extrator de $1: 2,5$

\subsubsection{Chumbo total}

A determinação do $\mathrm{Pb}^{2+}$ total foi feita de acordo com o método EPASW-846-3050, oficial da Agência de Proteção Ambiental dos Estados Unidos da América (USEPA - "United States Environmental Protection Agency), Amacher (1996). De forma resumida, a marcha analítica é descrita a seguir:

a). Pesar $1,0 \mathrm{~g}$ de terra transferir para etlenmeyer de $125 \mathrm{~mL}$ Adicionar 10 $\mathrm{mL}$ de $\mathrm{HNO}_{3}$ 1:1 bidestilado, misturar e cobrir com funil de vidro para haver refluxo do ácido dentro do erlenmeyer. A temperatura do bloco digestor deve ser ajustada para $95^{\circ} \mathrm{C}$. Deixar em refluxo por 15 minutos, sem ferver;

b) Esfriou, adicionar $5 \mathrm{~mL}$ de $\mathrm{HNO}_{3}$ concentrado, bidestilado. Aquecer sob refluxo por mais 30 minutos. Repetir a adição de $\mathrm{HNO}_{3}$ concentrado e aquecer por mais 30 minutos.

c) Evaporar a solução para $5 \mathrm{~mL}$ sem ferver e sem deixat secar a solução;

d) Esfriar, adicionar $3 \mathrm{~mL}$ de $\mathrm{H}_{2} \mathrm{O}_{2}$ a $30 \%$ e cobrir com o funil;

e) Aquecer a solução até ocorrer a reação com $\mathrm{H}_{2} \mathrm{O}_{2}$ a $30 \%$, esfriar; 
f) Adicionar $\mathrm{H}_{2} \mathrm{O}_{2}$ a $30 \%$, em alíquotas de $1 \mathrm{~mL}$ e aquecer até reação mínima com $\mathrm{H}_{2} \mathrm{O}_{2}$ a $30 \%$. Não adicionar mais que $6 \mathrm{~mL}$.

g) Adicionar $5 \mathrm{~mL}$ de $\mathrm{HCl}$ concentrado bidestilado e $10 \mathrm{~mL}$ de água deionizada bidestilada, deixar em refluxo por 15 minutos.

h) Esfriar e filtrar a solução em papel de filtro lavado com EDTA, 1+3 de $\mathrm{HCl}$ e água deionizada bidestilada. Diluir para balão volumétrico de 50 mL. Completar o volume com água bidestilada e deionizada.

Supondo-se que haveria possibilidade do íon $\mathrm{Cl}$ - formar complexo com o $\mathrm{Pb}^{2+}$, realizaram-se outras extrações, seguindo-se marcha analítica similar a anterior, sem a adição de $\mathrm{HCl}$ descrito no item " $\mathrm{g}$ ".

A quantificação de $\mathrm{Pb}$ no extrato foi feita por espectrometria de emissão atômica por indução de plasma (ICPAES), no Instituto Agronômico de Campinas IAC.

\subsubsection{Chumbo trocável}

O chumbo trocável no solo foi feito seguindo-se a metodologia proposta por Tessier et al. (1979), com as modificações propostas por Amacher (1996). Resumidamente, a marcha analítica compreende as seguintes etapas:

a) Pesar $1,0 \mathrm{~g}$ de terra e transferir para tubo plástico de $50 \mathrm{~mL}$;

b) Adicionar $20 \mathrm{~mL}$ de solução $0,1 \mathrm{~mol} \mathrm{~L}^{-1} \mathrm{de} \mathrm{Mg}\left(\mathrm{NO}_{3}\right)_{2}$;

c) Agitar por 2 horas à 180 rotações por minuto;

d) Centrifugar por 10 minutos à $1.500 \mathrm{rpm}$; 
e) Decantar e filtrar através de papel de filtro para remover a matéria orgânica sobrenadante.

Lavar o papel de filtro previamente com EDTA, $1+3$ de $\mathrm{HCl}$ bidestilado, e água deionizada bidestilada.

\subsection{Biodisponibilidade do chumbo}

O solo proveniente do experimento de incubação foi utilizado para a avaliação da fitodisponibilidade de $\mathrm{Pb}$ através de experimento tipo "Neubauer", preconizado por Neubauer \& Schneider (1923) e modificado por Catani \& Bergamin (1961).

Nesse experimento, $20 \mathrm{~g}$ do solo contendo o tratamento são misturados com $40 \mathrm{~g}$ de areia lavada e calcinada em placas de Petri de $8 \mathrm{~cm}$ de diâmetro e $2 \mathrm{~cm}$ de altura. Como planta teste, utilizou-se o arroz (Oryza sativa, L.), variedade IAC 4440 - irrigado.

Semearam-se uniformemente, em cada placa de Petri, 25 sementes de arroz pré-germinadas. Sendo que todos os tratamentos receberam solução nutritiva completa e a água perdida por evaporação era reposta diariamente por adição de água deionizada.

Após o periodo de 20 dias, as plantas foram retiradas (parte aérea + raizes + sementes não germinadas), lavadas com água corrente, $\mathrm{HCl} 0,1 \mathrm{~mol} \mathrm{~L}^{-1}$ bidestilado e água deionizada. Após a secagem em estufa à $45^{\circ} \mathrm{C}$, o material foi pesado e armazenado para análise.

As determinações de $\mathrm{Pb}^{2+}, \mathrm{Ca}^{2+}, \mathrm{Mg}^{2+}$ e $\mathrm{K}^{+}$, absorvidos pela planta. Determinaram-se o $\mathrm{Pb}$ segundo metodologia proposta por Amacher (1996), e os demais elementos, foram determinados segundo EMBRAPA (1999). 


\subsubsection{Chumbo no material vegetal}

A determinação do chumbo presente na planta foi feita utilizando-se a parte aérea mais raiz, seguindo a metodologia proposta por Amacher (1996), que é descrita resumidamente a seguir:

a) Pesar $0,5 \mathrm{~g}$ do material vegetal, incluindo parte aérea e raizes;

b) Transferir o material pesado para balões Kjeldahl de $50 \mathrm{~mL}$ e adicionar $5 \mathrm{~mL}$ de $\mathrm{HNO}_{3}$ concentrado bidestilado, deixar em capela por um dia para que houvesse maior reação ácido-material vegetal;

c) Digerir em bloco digestor com temperatura ajustada para $95^{\circ} \mathrm{C}$;

d) Deixar sob aquecimento até o aparecimento de fumos brancos;

e) Esfriar, adicionar $5 \mathrm{~mL}$ de água bidestilada deionizada e reteve-se para determinações.

Nos extratos obtidos determinaram-se $\mathrm{Pb}^{2+}, \mathrm{Ca}^{2+}, \mathrm{Mg}^{2+}$ e $\mathrm{K}^{+} . \mathrm{A}$ determinação de $\mathrm{Pb}^{2+}$ foi feita por espectrofotometria de absorção atômica em forno de grafite (GFAAS), no Centro de Energia Nuclear na Agricultura - CENA/USP.

$\mathrm{Ca}^{2+}$ e $\mathrm{Mg}^{2+}$ foram determinados por espectrofotometria de absorção atômica em chama (FAAS) e $\mathrm{K}^{+}$por fotometria de chama. 


\section{RESULTADOS E DISCUSSÃO}

\subsection{Resíduo-corretivo e matéria orgânica nos atributos do solo}

$\mathrm{O}$ teor de $\mathrm{Pb}$ total presente nos tratamentos (Figura 1) mostra o potencial de acúmulo do elemento no solo pela adição de doses crescentes do resíduo. Esse efeito é função da presença do metal na composição deste material (item 3.1.3). Entretanto os valores obtidos para $\mathrm{Pb}$ total não atingiram, com uma única aplicação, os valores críticos de concentração de $\mathrm{Pb}$ total no solo que varia entre 100 e $400 \mathrm{mg}$ g-1 (Kabata-Pendias \& Pendias, 1984).

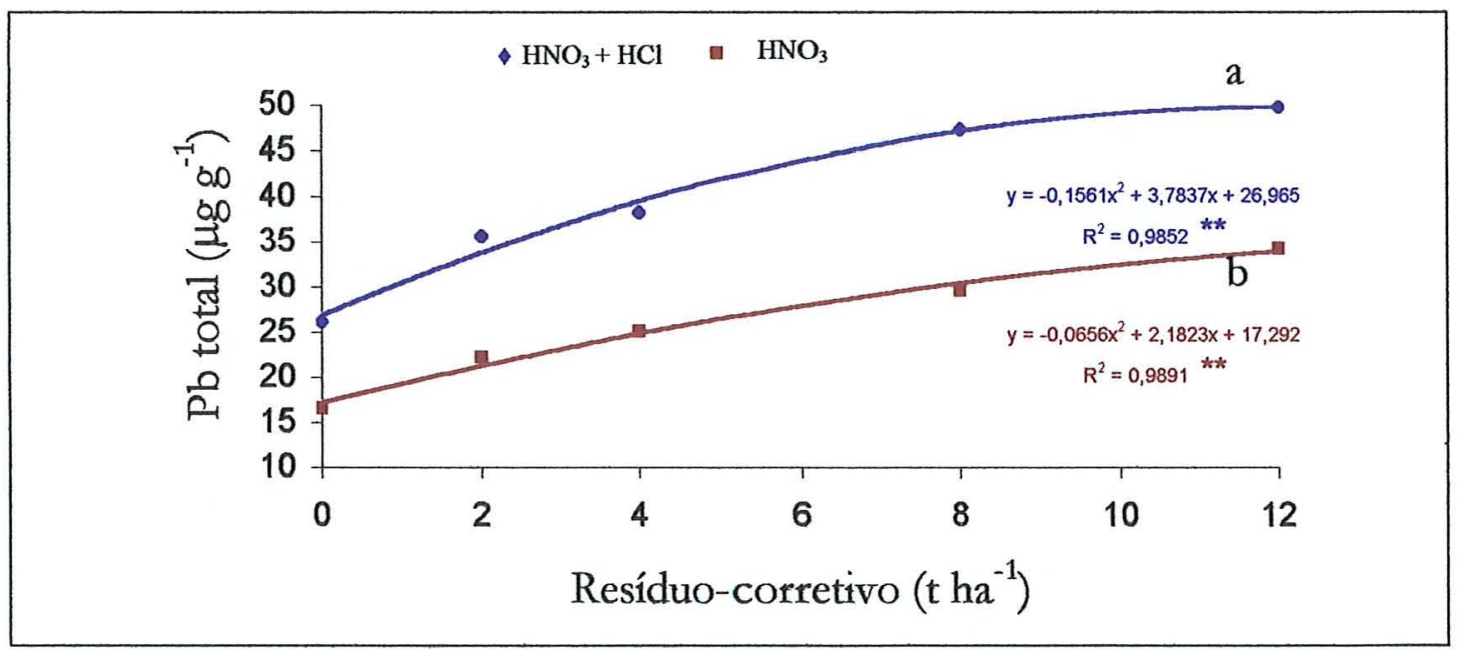

Figura 1. Teor de $\mathrm{Pb}$ total, em função da dose do resíduo aplicada, e do extrator. (** Significativo a $1 \%$, C.V.: (a) 7,68\%; (b) 8,87\%). 
Ainda com relação aos valores apresentados na Figura 1, convém salientar que, a extração do $\mathrm{Pb}$ total via $\mathrm{HNO}_{3}$ mostrou-se mais eficiente, uma vez que os valores encontrados com a extração utilizando $\mathrm{HNO}_{3}+\mathrm{HCl}$ não condizem com a quantidade de $\mathrm{Pb}$ adicionada, demonstrando haver interferência do íon $\mathrm{Cl}^{-}$ superestimando os resultados. A interferência do ânion cloreto na determinação do $\mathrm{Pb}$ foi observada por Amacher (1996).

Amaral Sobrinho et al. (1997), observaram o poder contaminante do resíduo-corretivo Paracatú e relataram que a sua aplicação, em dose de $2,5 \mathrm{t}$ ha-1, resultou no aumento dos teores totais de $\mathrm{Pb}, \mathrm{Cd}$ e $\mathrm{Zn}$ do solo. Observaram também, aumento nos teores trocáveis desses elementos, entretanto atribuíram esse aumento a problemas metodológicos devido ao extrator empregado ( $\mathrm{NaOAc} 1 \mathrm{~mol} \mathrm{~L}^{-1}$ ).

Os teores de $\mathrm{Pb}$ trocável no solo foram influenciados tanto pelas doses do resíduo-corretivo quanto pelas doses da fonte orgânica utilizada, esterco bovino (Figura 2).

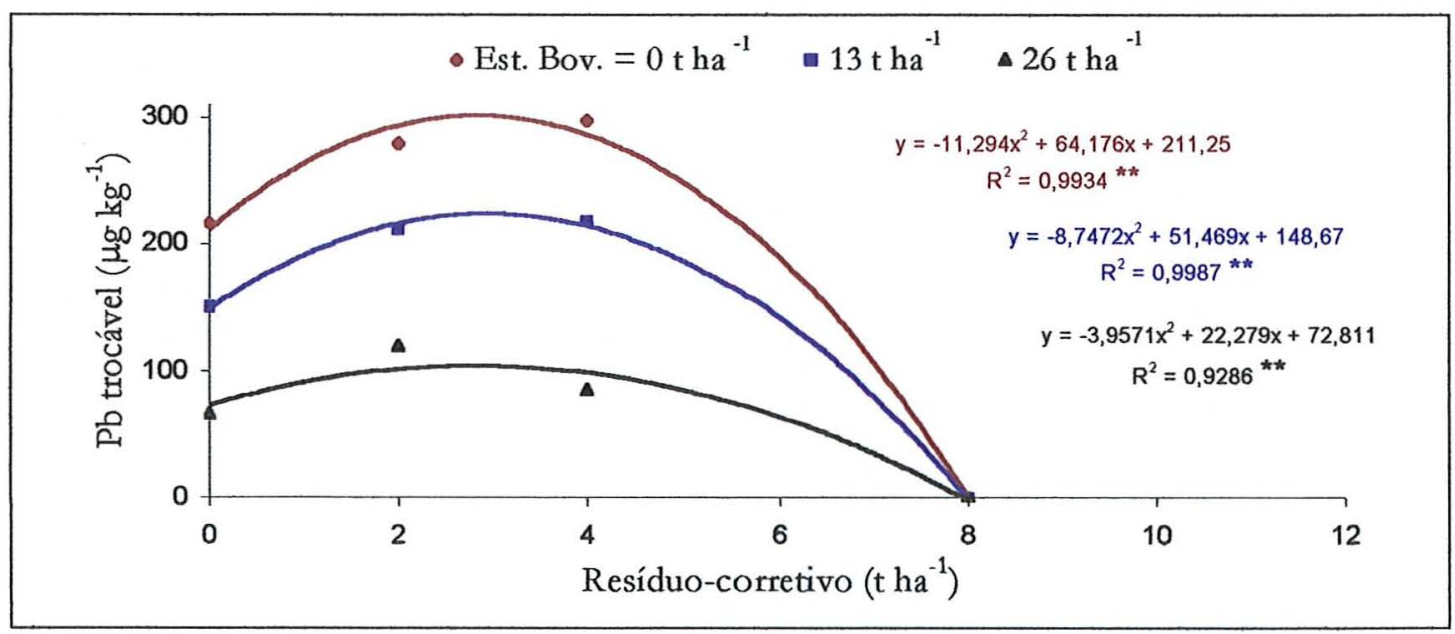

Figura 2. Teores de chumbo trocável em função da dose do resíduo-corretivo, sob adição de matéria orgânica. (Est. Bov. = Esterco bovino. ** Significativo a $1 \%$. C.V.: 15,16\%). 
A adição do resíduo-corretivo ao solo nas doses de 2 e $4 \mathrm{t} \mathrm{ha}^{-1}$, resultou numa elevação progressiva dos teores de $\mathrm{Pb}$ trocável nos tratamentos que atingiram, na dose $4 \mathrm{t} \mathrm{ha}^{-1} \mathrm{sem}$ material orgânico, $298 \mu \mathrm{g} \mathrm{g}^{-1}$. Para a mesma dose do resíduo a adição do material orgânico reduziu o teor de $\mathrm{Pb}$ trocável para $85 \mu \mathrm{g} \mathrm{g}^{-1}$. A partir da dose de $4 \mathrm{t} \mathrm{ha}^{-1}$ do resíduo-corretivo, os teores de $\mathrm{Pb}$ trocáveis decrescerata, atingindo valor abaixo do limite de determinação do equipamento utilizado na sua quantificação, na dose de $8 \mathrm{tha}^{-1}$. Isso significa que nesses tratamentos o teor de $\mathrm{Pb}$ trocável nos extratos analisados era inferior a $100 \mu \mathrm{g} \mathrm{L}^{-1}$. Esse decréscimo no teor de $\mathrm{Pb}$ trocável do solo em função da fonte orgânica pode ser observado também para o elemento originalmente presente no solo.

$\mathrm{O}$ aumento nos valores de $\mathrm{pH}$ do solo, diretamente proporcional às doses do resíduo-corretivo (Figura 3), foi influenciado pela fonte orgânica que impôs uma diferença de comportamento a partir da dose $8 \mathrm{t} \mathrm{ha}^{-1}$ do resíduo-corretivo. Para as mesmas doses do resíduo, os tratamentos com aplicação de matéria orgânica resultaram num menor valor de $\mathrm{pH}$, o que pode ser atribuído ao poder tampão do material orgânico. O efeito do poder tampão da matéria orgânica é relatado por vários autores, e se deve ao aumento de sítios de troca e da atividade hidrogeniônica no solo (Kiehl, 1985; Tan, 1990).

A solubilidade do chumbo depende da forma em que o mesmo se encontra no solo, sendo o valor $\mathrm{pH}$ uma das características do solo que mais a afeta. A formação de compostos pouco solúveis de $\mathrm{Pb}$, do qual os mais importantes seriam $\mathrm{PbCl}_{2}\left(\mathrm{Ks}=1,6.10^{-5}\right)$ e $\mathrm{PbHPO}_{4}\left(\mathrm{Ks}=1,3.10^{-19}\right)$, pode ser um dos fatores que provocaram a redução no teor de $\mathrm{Pb}$ trocável do solo, já que o $\mathrm{pH}$ do meio não possibilita a formação de hidróxidos e carbonatos. Também a co-precipitação do metal junto a óxidos de $\mathrm{Fe}$ e $\mathrm{Al}$ pode explicar o decréscimo do teor solúvel do elemento, verificada a partir de $\mathrm{pH} 5,6$, com a aplicação de doses a partir de $4 \mathrm{t}$ ha-1 do resíduo-corretivo. A formação de compostos pouco solúveis e também a coprecipitação tem sido usada por diversos autores para explicar o decréscimo do teor 
de metais pesados em solos (Albasel \& Cottenie, 1985; Sposito, 1989; Artega, 1996; Melo et al., 1997 e Berton, 2000).

Com a adição dos agentes complexantes fornecidos pela fonte orgânica, a quantidade de $\mathrm{Pb}$ trocável foi diminuída em relação à apresentada pelos tratamentos com resíduo, o que demonstra a importância dos ligantes na redução da quantidade disponível do elemento. A reação do cátion metálico organicamente complexado, provavelmente, deve ser diferente em relação ao inorganicamente complexado, pelo fato de que as reações de complexação neutralizam a carga positiva do cátion metálico (Singh \& Pandeya, 1998).

A formação de complexos estáveis entre metais e ligantes orgânicos, segundo Alleoni (2000), é um importante fator que afeta o comportamento de metais em solos ácricos. Kabata-Pendias \& Pendias (1984) e Abreu et al. (1998), atribuíram a baixa biodisponibilidade do $\mathrm{Pb}$ e a acumulação nos horizontes superficiais à elevada capacidade de complexação do $\mathrm{Pb}$ pela matéria orgânica.

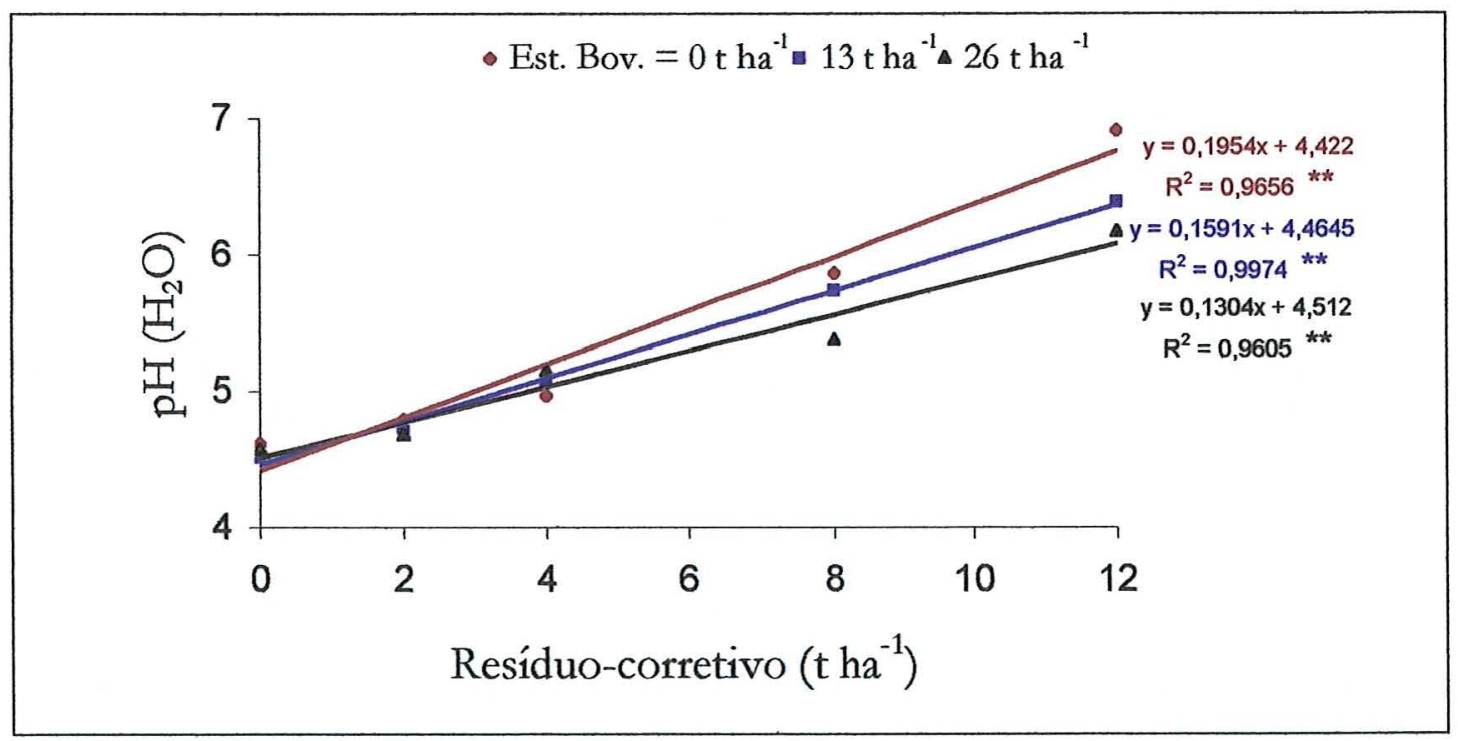

Figura 3. Efeito da dose do resíduo-corretivo sobre o $\mathrm{pH}$, em função da dose de matéria orgânica adicionada. (Est. Bov. = Esterco bovino. ** Significativo a $1 \%$. C.V.: $2,15 \%$.) 
Houve redução nos teores de $\mathrm{Al}$ trocável com o aumento das doses do resíduo-corretivo e com a adição da fonte de matéria orgânica (Figura 4). Considerando-se que o material orgânico adicionado não provocou alterações nos valores de $\mathrm{pH}$ do solo nas três menores doses do resíduo-corretivo, o decréscimo no teor de $\mathrm{Al}$ trocável pode ser explicado pela complexação desse cátion por ligantes orgânicos. A formação de complexos entre $\mathrm{Al}^{3+}$ e ligantes orgânicos tem sido relatada pela literatura para explicar o decréscimo no teor de $\mathrm{Al}$ trocável quando não há elevação do pH do meio (Tan, 1990; Miyazawa et al., 2000). A partir da dose de 8 t ha $\mathrm{h}^{-1}$ do resíduo-corretivo não foi observado Al trocável no solo, sendo que nesses tratamentos o $\mathrm{pH}$ era de 5,6 e acima.

Segundo Miyazawa et al. (2000) a complexação do $\mathrm{Al}^{3+}$ ocorre pela ação dos ácidos orgânicos, os quais apresentam diferentes capacidades de neutralização da toxidez de Al. Os mais eficientes são aqueles que formam complexos estáveis, ou seja, aqueles que apresentam alto valor de constante de estabilidade, e os ineficientes são os que possuem baixa constante de estabilidade, sendo seus efeitos quase nulos.

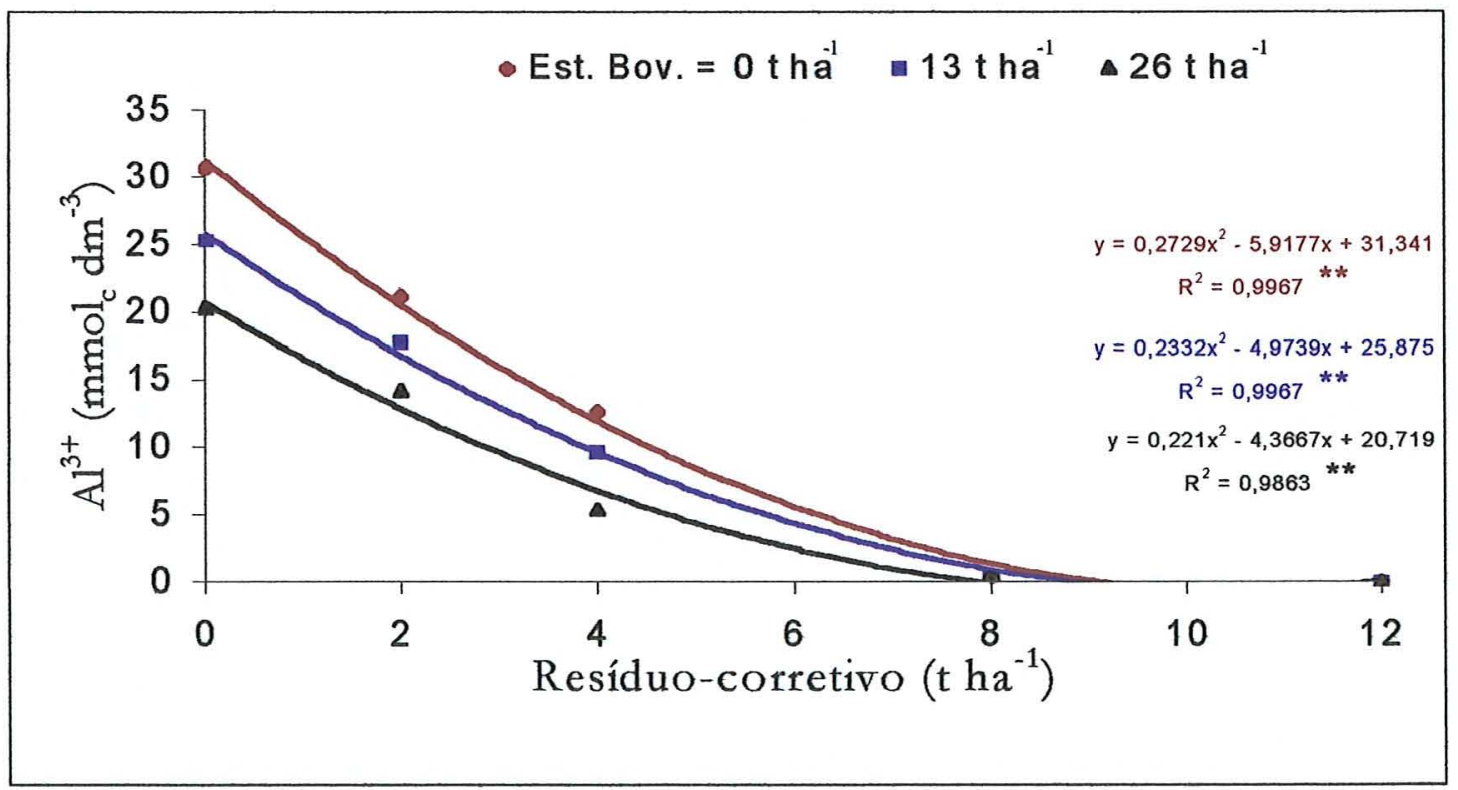

Figura 4. Efeito da do se de resíduo-corretivo no teor de $\mathrm{Al}^{3+}$ trocável, sobre adição de matéria orgânica. (Est. Bov. = esterco bovino. ** Significativo a $1 \%$. C.V.: 7,87 \%). 
Gonçalves et al. (2000), em experimento realizado à campo utilizando biossólido em doses de até $40 \mathrm{t} \mathrm{ha}^{-1}$, observaram que com o aumento de doses de biossólidos aplicadas ao solo há redução nos teores de $\mathrm{Al}$, Fe e $\mathrm{Mn}$, sem que houvesse alteração significativa nos valores de $\mathrm{pH}$, o que seria uma evidência do efeito da complexação do Al trocável pelas compostos orgânicos adicionados via biossólido.

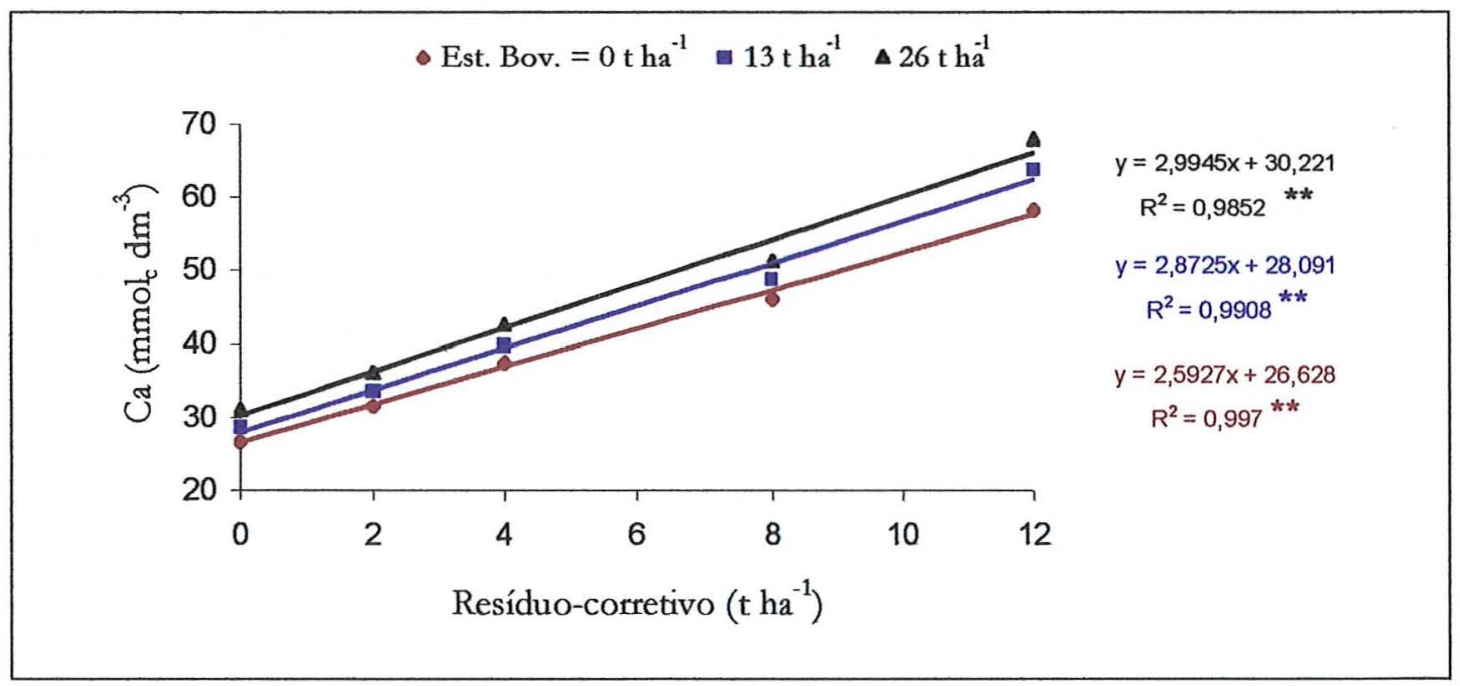

Figura 5. Teores de $\mathrm{Ca}^{2+}$ trocável em função da dose do resíduo-corretivo aplicada, sob adição de esterco bovino. (Est. Bov. = Esterco bovino. ** Significativo a $5 \%$. C.v.: $2,99 \%$ ).

Para os teores de Ca no solo, foi observada uma interação significativa entre as doses de resíduo-corretivo e matéria orgânica (Figura 5), o que não foi observado para os teores de $\mathrm{Mg}$ (Figura 6). 

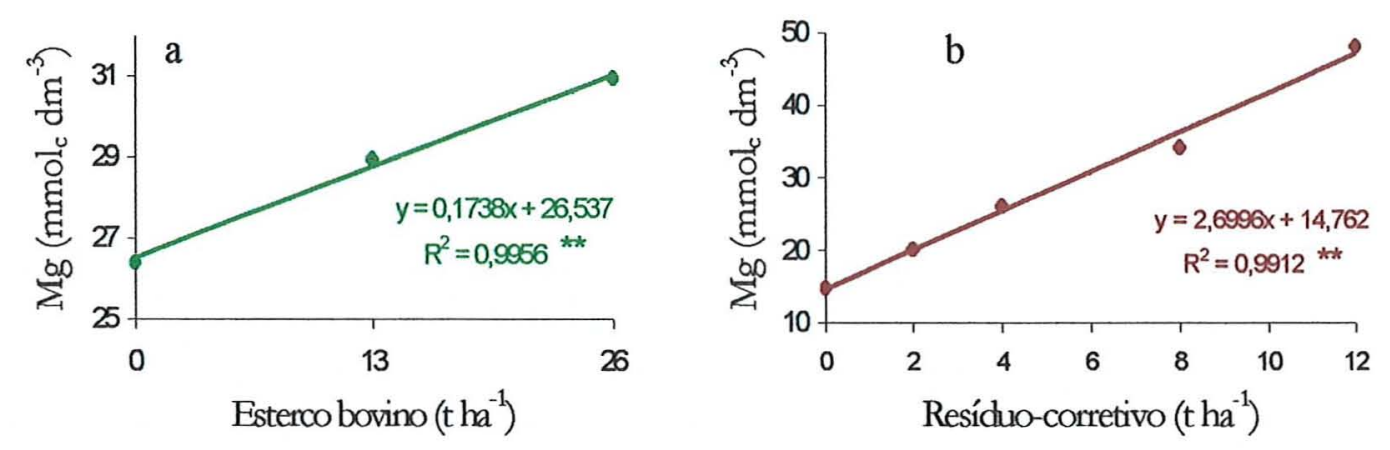

Figura 6. Influência da dose de esterco bovino(a) e resíduo-corretivo(b) no teor de Mg. (** Significativo a $1 \%$. C.v.: 4,07 \%).

A elevação nos teores de $\mathrm{Ca}^{2+}$ e $\mathrm{Mg}^{+2}$ no solo, devem-se a ao fato do resíduo-corretivo e do esterco bovino conterem esses elementos (item 3.1.2) Os acréscimos observados em função da fonte de matéria orgânica, tanto para o $\mathrm{Ca}^{2+}$ quanto para $\mathrm{o} \mathrm{Mg}^{2+}$, foram estatisticamente significativos, porém, pouco relevante comparando-se com a quantidade que os corretivos de solos proporcionam, uma vez que os principais nutrientes contidos na matéria orgânica, de um modo geral, são: $\mathrm{N}$, P, S e B.

\subsection{Resíduo-corretivo e material orgânico nos teores de $\mathrm{Pb}, \mathrm{Ca}$ e $\mathrm{Mg}$ no material vegetal}

A concentração de $\mathrm{Pb}$ na planta não foi correspondente ao comportamento observado para $\mathrm{Pb}$ trocável no solo. Com o aumento da dose do resíduo-corretivo, houve aumento nas quantidades de $\mathrm{Pb}$ absorvidas pelas plantas de arroz, o que evidencia a disponibilidade do elemento presente no solo. Essa disponibilidade pode ser atribuída à liberação de exsudados de raízes, os quais 
disponibilidade pode ser atribuida à liberação de exsudados de raízes, os quais através de ácidos orgânicos, acidificam a rizosfera e assim liberam metais que, em outras situações, não estariam prontamente disponíveis para as plantas. Outra explicação pode ser atribuída à liberação pelas raizes de ligantes orgânicos que formam complexos de alta estabilidade com metais, incluindo-se o $\mathrm{Pb}$, capazes de serem absorvidos pelas plantas, como é o caso do ácido mugeínico que foi isolado de plantas de aveia (Godo \& Reisenauer, 1980; Merckx et al., 1986; Mench \& Martin, 1991; Bowen \& Rovira, 1991; Krishnamurti et al., 1997; Hinsinger, 1999; Berton, 2000). Outros ácidos orgânicos de baixo peso molecular, como o acético, ćtrico, oxálico, fumárico e succínico, geralmente presentes nos exsudados de raízes, também tem sido relatados como eficientes na solubilização de metais presentes no solo (Merckx et al., 1986). Os resultados obtidos evidenciam a inadequação do uso do extrator $\mathrm{Mg}\left(\mathrm{NO}_{3}\right)_{2}$ na previsão da fitodisponibilidade do elemento. Isso mostra a necessidade de estudos que identifiquem extratores mais eficientes nessa previsão.

Assumindo-se que a solubilização pelos exsudados de raizes é fundamental para a absorção de metais pela planta, em se identificando a composição química desses para culturas, poder-se-ia utilizá-los para estimar com precisão as quantidades biodisponíveis totais dos metais presentes no solo (Berton, 2000). 


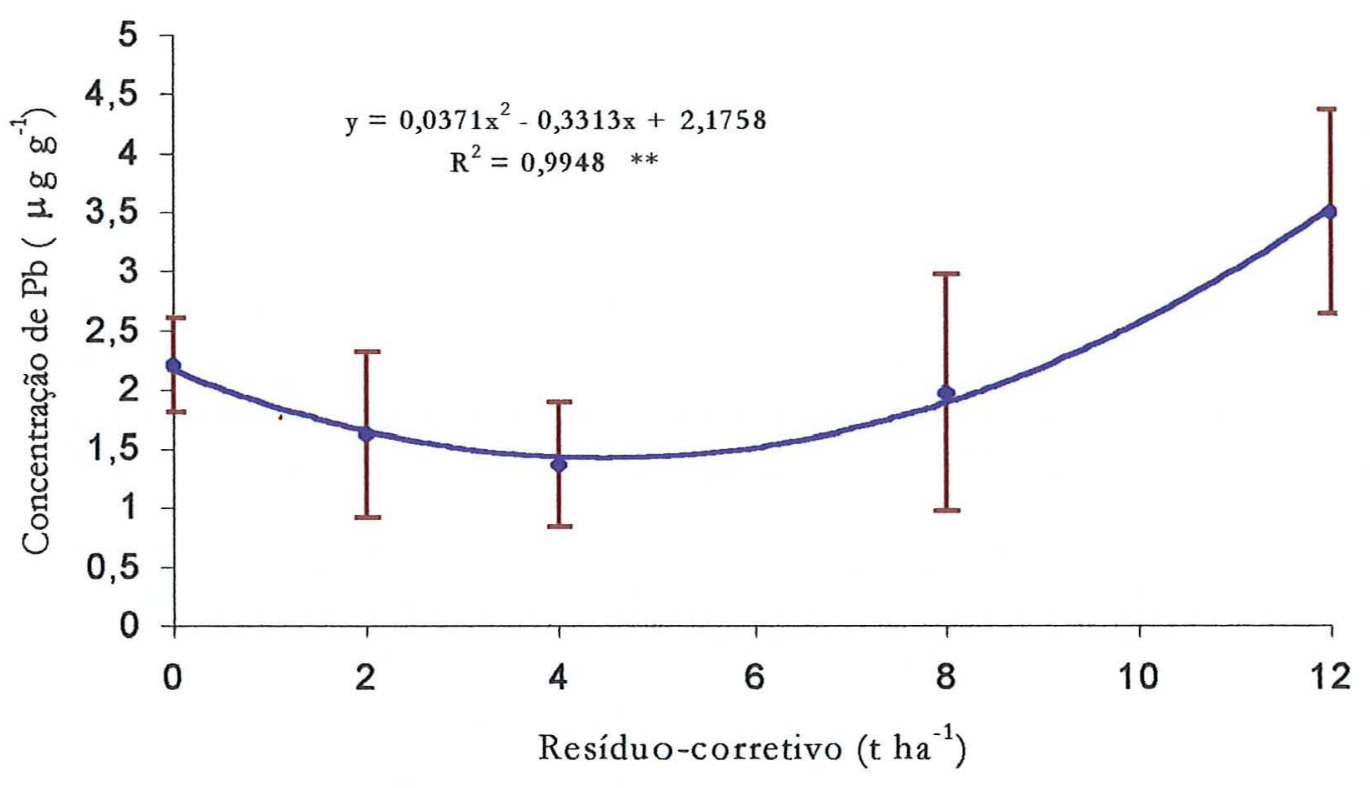

Figura 7. Teor de chumbo absorvido em função da dose de resíduo-corretivo aplicada. (** Significativo a $1 \%$. C.v.: 31,65\%.)

$\mathrm{O}$ teor de $\mathrm{Pb}$ presente nas plantas, mesmo nas situações de ausência de teores trocáveis desse elemento no solo, encontram-se abaixo da faixa de normalidade, citada por Kabata-Pendias \& Pendias (1984), que é de 5 a $10 \mu \mathrm{g} \mathrm{g}^{-1}$. Os mesmos autores citam que os valores críticos estão entre 30 e $300 \mu \mathrm{g} \mathrm{g}^{-1}$.

Os teores de Ca e $\mathrm{Mg}$ aumentaram no tecido vegetal com o aumento das doses aplicadas do resíduo-corretivo (Figura 8), evidenciando a estreita relação existente entre teor do elemento disponível no solo e teor absorvido pela planta. Com relação à absorção desses elementos, tem sido relatado pela literatura o efeito dos teores de $\mathrm{Al}^{3+}$ no solo que inibem a absorção de Ca pelo bloqueamento dos canais na membrana plasmática (Huang, 1992). Além disso, o $\mathrm{Al}^{3+}$ impede a absorção de $\mathrm{Mg}$, por bloquear os sítios de ligação desse nutriente às proteínas transportadoras (Rengel \& Robinson, 1989). 


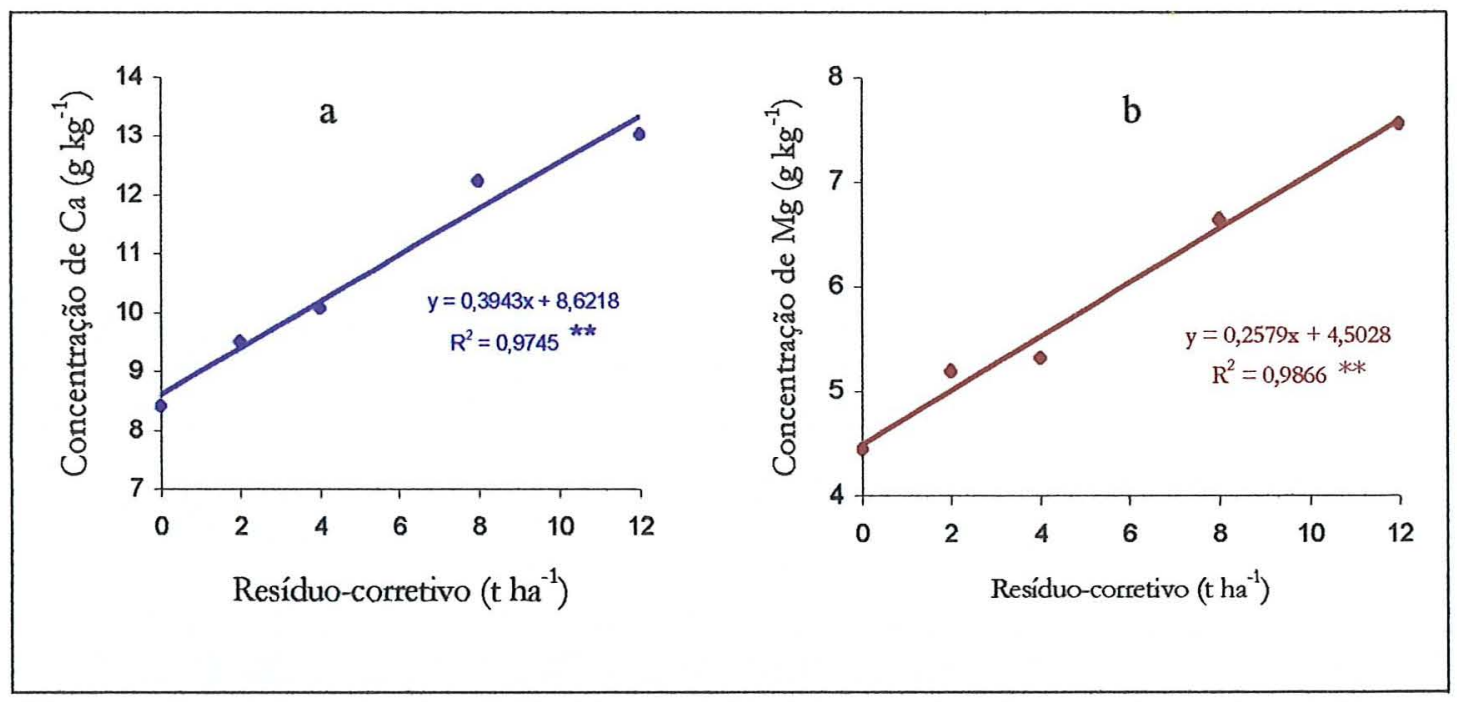

Figura 8. Absorção de $\mathrm{Ca}^{2+}$ (a) e $\mathrm{Mg}^{2+}$ (b) em função da dose do resíduocorretivo aplicada. (** Significativo a $1 \%$, C.v.: (a) $12,05 \%$; (b) $18,56 \%)$.

Ainda com respeito à absorção de $\mathrm{Ca} \mathrm{e} \mathrm{Mg}$, não foi verificada influência do teor de matéria orgânica na absorção dos mesmos.

Os resultados obtidos nesse trabalho são semelhantes aos encontrados por Gonçalves et al. (2000), em estudos com biossólidos. À medida que se elevaram as doses do resíduo, houve uma nítida elevação das concentrações de $\mathrm{Ca}$ e $\mathrm{Mg}$ no solo, o que resultou em variações na composição química do tecido foliar, aumentando o teor de $\mathrm{Ca}$ e diminuindo os teores de Fe e Mn. 


\section{CONSIDERAÇÕES GERAIS}

$\mathrm{O}$ teor de $\mathrm{Pb}$ total foi dependente do teor original do solo, e da dose do resíduo-corretivo aplicada estes valores mostram o alto potencial poluente do resíduo.

O material orgânico adicionado não promoveu elevação nos valores de $\mathrm{pH}$ do solo nos tratamentos com resíduo-corretivo, e provocou redução no teor de $\mathrm{Pb}$ trocável.

A extração do $\mathrm{Pb}$ total por $\mathrm{HNO}_{3}$ mostra-se mais eficiente na determinação do mesmo em espectroscopia de emissão atômica por indução de plasma (ICPAES), para a faixa de valores $\mathrm{pH}$ de solos agrícolas.

$\mathrm{O}$ resíduo-corretivo foi eficiente na correção da acidez do solo e no fornecimento de $\mathrm{Ca}$ e $\mathrm{Mg}$. Para solos que receberam o resíduo-corretivo contaminado por $\mathrm{Pb}$, o teor trocável do elemento não reflete a fitodisponibilidade do mesmo, exigindo o desenvolvimento de extratores específicos.

A utilização do resíduo-corretivo Paracatú pode ser feita de forma a não ultrapassar a dose de $4 \mathrm{t} \mathrm{ha-1}$ que foi a que apresentou, em função do $\mathrm{pH}$ e teor de matéria orgânica presente, a menor disponibilidade do elemento para as plantas. Todavia não devem ser esquecidos o monitoramento do solo e plantas para prevenir a poluição de solo e passagem do elemento para a cadeia alimentar. Nesse monitoramento é fundamental observar o teor total de $\mathrm{Pb}$ adicionado, teor original $\mathrm{e}$ matéria orgânica do solo, bem como valor de $\mathrm{pH}$ do solo. 


\section{CONCLUSÃo}

A adição do resíduo corretivo foi acompanhada de aumento nos valores de $\mathrm{pH}$ do solo, no teor de $\mathrm{Pb}$ total e redução no teor de $\mathrm{Pb}$ trocável.

A adição de matéria orgânica proporcionou uma maior redução no teor de $\mathrm{Pb}$ trocável presente no solo. Apesar do decréscimo no teor de $\mathrm{Pb}$ trocável, o elemento foi absorvido por plantas de arroz, o que demonstra a sua disponibilidade e a inadequação do extrator utilizado, $\mathrm{Mg}\left(\mathrm{NO}_{3}\right)_{2}$ 0,01 $\mathrm{mol} \mathrm{L} \mathrm{L}^{-1}$, na previsão da biodisponibilidade. 


\section{REFERÊNCIAS BIBLIOGRÁFICAS}

ABD-ELFATTAH, A.; WADA, $\mathrm{K}$ Adsorption of lead, copper, zinc, cobalt and cadmium by soils that differ in cation-exchange materials. Journal of Soil Science, 32:271-283, 1981.

ABREU, C.A. de; ABREU, M.F. de; ANDRADE, J.C. de. Distribuição de chumbo no perfil de solo avaliada pelas soluções de DTPA e Mehlich-3. Bragantia, 57(1):185-192, 1998.

ADRIANO, D.C. Trace Elements in The Terrestrial Environment. Springer Verlag. Nova Iorque, 1986. 533p.

ALBASEL, N.; COTTENIE, A. Heavy metals uptake from contaminated soils as affected by peat, lime and chelates. Soil Sci. Soc. Am. J., 49:386-390, 1985.

ALLEONI, L.R.F. Química de latossolos ácricos. Piracicaba: ESALQ-USP, 2000. Tese Livre-Docência 121 p.

ALLOWAY, B.J. Cadmium. In: ALLOWAY, B.J. Heavy metals in soils. 1.ed. Glasgow, Blackie Academic \& Professional, 1990. p. 100-124.

ALVES, M.C.; CASTRO, O.M.; LOMBARDI NETO, F. Sistemas de rotação de culturas com plantio direto em Latossolo Roxo: Efeitos nas propriedades químicas e produtividade da soja (Glycine max L. Merrill). In: ENCONTRO LATINO AMERICANO SOBRE PLANTIO DIRETO NA PEQUENA PROPRIEDADE, 1, 1993, Ponta Grossa, PR. Anais... Ponta Grossa: IAPAR, 1993. p. 203-214.

AMACHER, M.C. Nickel, Cadmium and Lead. In SPARKS, D.L. (ed.) Methods of soil analysis: Chemical Methods; Part 3, Soil Science Society of America; America Society of Agronomy, 1996, p.739-769. 
AMARAL SOBRINHO, N.M.B. Interação dos Metais Pesados de Resíduos Siderúrgicos com um Solo Podzólico Vermelho-Amarelo. Viçosa, MG: UFV, 1993. 163p. Tese Doutorado - Universidade Federal de Viçosa, 1993.

AMARAL SOBRINHO, N.M.B.; COSTA, L.; OLIVEIRA, C.; VELLOSO, A.C.X. Metais Pesados em alguns fertilizantes e corretivos. R. bras. Ci. Solo, 16:271$276,1992$.

AMARAL SOBRINHO, N.M.B.; GOMES. M.F.; VELLOSO, A.C.X.; OLIVEIRA, C. Fracionamento de zinco e chumbo em solos tratados com fertilizantes e corretivos. R. bras. Ci. Solo, 21:17-21, 1997.

ARTEGA, D.H., Dinâmica de Cádmio, Chumbo, Cobre, Niquel e Zinco no Sistema Solo - Planta. Viçosa, MG: UFV, 1996. 90p. Dissertação Mestrado Universidade Federal de Viçosa.

BERTON, R.S. Riscos de contaminação do agtoecossistema com metais pesados. In: BETTIOL, W. \& CAMARGO, O.A. (ed.). Impacto ambiental do uso agrícola do lodo de esgoto. EMBRAPA - Meio Ambiente e IAC, 2000. p. 179-95.

BERTON, R.S.; VALADARES, J.M.A.S.; CAMARGO, O.A. de; BATAGLIA, O.C. Peletização do lodo de esgoto e adição de $\mathrm{CaCO}_{3}$ na produção de matéria seca e absorção de $\mathrm{Zn}, \mathrm{Cu}$ e Ni pelo milho em três latossolos. R. bras. Ci. Solo, 21:685-691, 1997.

BOWEN, G.D.; ROVIRA, A.D. The rhizosphere. The hidden half of hidden half. In: WEISEL, Y.; ESHEL, A.; KAFKAFI, U. Plant roots - the ridden half. New York: Marcel Dekker, 1991. p. 641-669.

BRASIL, Ministério da Agricultura. Inspeção e fiscalização da produção e do comércio de fertilizantes, corretivos, inoculantes, estimulantes e biofertilizantes destinados à agricultura - Legislação e fiscalização. 
Brasilia: Secretaria Nacional de Defesa Agropecuária, Divisão de Corretivos e Fertilizantes, $1982.88 \mathrm{p}$.

BRASIL. Ministério da Agricultura. Secretaria Nacional de Defesa Agropecuária. Análise de fertilizantes, corretivos e inoculantes; Métodos Oficiais. Brasilia, 1988, 104p.

BROWN, S.L.; CHANEY, R.L.; ANGLE, J.S.; RYAN, J.A. The phytoavailability of cadmium to lettuce in long-term biossolids-amended soils. Journal of Environmental Quality, 27:1071-1078, 1998.

BURAK, D.L.; FONTES, M.P.F. Adsorção simultânea de cádmio, zinco, cobre e chumbo em dois Latossolos de Minas Gerais. In: FERTIBIO 2000, REUNIÃO BRASILEIRA DE FERTILIDADE DO SOLO E NUTRIÇÃO DE PLANTAS, 24. Santa Maria, RS. 2000. Resumo em CD-ROM; 2000.

CAMARGO, O.A. Complexos de metais pesados com substâncias húmicas e matéria orgânica: estabilidade das ligações. In: ENCONTRO BRASILEIRO DE SUBSTÂNCIAS HÚMICAS, 2., São carlos, 1997. Anais. São carlos: EMBRAPA, CNPDIA, 1997. p. 72-73.

CAMARGO, O.A.; VALADARES, J.M.A.S.; BERTON, R.S.; TEÓFILO SOBRINHO, J.; MENK, J.R.F. Alteração de características químicas de um Latossolo Vermelho-Escuro distrófico pela aplicação de vinhaça. Campinas: IAC, 1987. 23p. (IAC. Boletim Científico, 9).

CAMBUIM, F.A.; CORDEIRO, D.A. Açaõ da vinhaça sobre $\mathrm{pH}$, acidez total, acumulação e lixiviação de nutrientes em solo arenoso. Stab Açúcar e Álcool e Subprodutos, 4:27-33, 1986.

CANÃDAS, R.C.; SANCHIDRIAN, J.R; RIVERO, V.C. Distribicion de Pb, Cd, $\mathrm{Cu}$ y $\mathrm{Cr}$ entre distintas fases solidas en algunos tipos de suelos. Anales de Adafologia y Agrobiologia, p.613-630, 1986. 
CASSIOLATO, M.E.; MEDA, A.R; PAVAN, M.A. \& MIYAZAWA, M. A laboratory method to estimate the efficiency of plant extract to neutralize soil acidity. CONGRESSO LATINO AMERICANO DE LA CIENCIA DEL SUELO, 14, Temuco, 1999. Temuco: SLACS/UF/SAC/SCS, 1999. Resumo, 361.

CATANI, R.A. \& BERGAMIN FILHO, H. Sobre uma modificação no método de NEUBAUER. Anais da Escola Superior de Agricultura "Luiz de Queiroz”, 18:287-300, 1961.

CATANI, R.A. \& JACINTHO, A.O. Avaliação da fertilidade do solo, métodos de análise. Piracicaba, Livroceres, 1974. 61 p.

COSTA, E.O. Adsorção e competição de alguns metais por ácidos húmicos extrardos de um latossolo húmico da região de Araponga. Viçosa-MG, UFV, 1991. 71 p. Tese Mestrado.

DANA, J.D. Manual de mineralogia. Rio de Janeiro, Livros Técnicos e Científicos, 1978. 642p.

DAVIS, R.D.; BECKETT, P.H.T; NOLLAW, E. Critical levels of twenty potentially toxic elements in young spring barley. Plant and Soil, 49:395-408, 1988.

EATON, A.D.; CLESCERI, L.S.; GREENBERG, A.E. Standard methods for the examination of water and wastewater. $19^{\text {th }} \mathrm{ed} 1995$.

ELLIOTT, H.A. ; LIBERATTI, M.R. ; HUANG, C.P. Effect of Iron Oxide Removal or Heavy Metal Sorpition by. Acid Subsoils. Water Air Soil Pollution, 37: 379-389, 1986.

ELLIS, B.G. \& KNEZEK, B.D. Adsorptions reactions of micronutrients in soils. In: DINAVER, R.C. (ed.) Micronutrients in agriculture, Madison, SSSA, 1977. 566 p. 
Empresa de Pesquisa Agropecuária Brasileira (EMBRAPA). Empresa Brasileira de Pesquisa Agropecuária. Manual de Análises químicas de solos, plantaș e fertilizantes. Brasilia: Ministério da Agricultura e Abastecimento. 1999. 370 p.

EPSTEIN, E.; TAYLOR, J.M.; CHANEY, R.L. Effects of sewage slude and slude compost applied to soil on some soil physical and chemical properties. J. Environ. Qual., 5:422-26, 1976.

FONTES, M.P.F. Caracterização da carga elétrica superficial de partículas do solo. (compact disc) In: CONGRESSO LATINO AMERICANO DE CIÊNCIA DO SOLO, 13., Águas de Lindóia, 1996. Solo-suelo 96: trabalhos. Piracicaba: SBCS/SLCS, 1996.

FONTES, M.P.F.; MATOS, A.T. de; COSTA, L.M. da e NEVES, J.C.L. Competitive adsorption of $\mathrm{Zn}, \mathrm{Cd}, \mathrm{Cu}$ and $\mathrm{Pb}$ in three highly weathered Brazilian soils. Commun. Soil Sci. Plant Anal., 31: (In Press), 2000.

FORBES, E.A.; POSNER, A.M.; QUIRK, J.P. The specific adsorption of divalent $\mathrm{Cd}, \mathrm{Co}, \mathrm{Cu}, \mathrm{Pb}$ and $\mathrm{Zn}$ on goethite. Journal of Soil Science, 27:154-166, 1976.

FOY, C.D. Effects of aluminum on plant growth. In: CARSON, E.W., ed. The plant root and its environment. 2. Ed. Charlottesville, University Press of Virginia, 1974. p. 601-42.

FOY, C.D. Soil chemical factors limiting plant root growth. In: HATFIEL, J.L. \& STEWART, B.A. Limitations to plant root growth. New York, SpringerVerlag, 1992. p. 97-149.

FRANCHINI, J.C.; MALAVOLTA, E.; MIYAZAWA, M.; PAVAN, M.A. Alterações químicas em solos ácidos após a aplicação de resíduos vegetais. $\mathbf{R}$. bras. Ci. Solo, 23:533-42, 1999b. 
FRANCHINI, J.C.; MTYAZAWA, M.; PAVAN, M.A. \& MALAVOLTA, E. Dinâmica de íons em solo ácido lixiviado com extratos de resíduos de adubos verdes e soluções puras de ácidos orgânicos. Pesq. agropec. bras., 34:2267$76,1999 \mathrm{a}$.

FURLANI, P.R. \& BERTON, R.S. Atividade de cálcio e alumínio e desenvolvimento radicular. In: SEMINÁRIO SOBRE O USO DO GESSO NA AGRICULTURA, 2., Uberaba, 1992. Anais. Uberaba. IBRAFOS, 1992 p.121-38.

GADDE, R.R.; LAITINEN, H.A. Studies of heavy metal adsorption by hydrous iron and manganese oxides. Analytical Chemistry, 46:2022-26, 1974.

GODO, G.H.; HEISENAUER, H.M. Plant effects on soil manganese availability. Soil Science Society of America Journal, 44:993-95, 1980.

GOMES, P.C. Fracionamento e Biodisponibilidade de Metais Pesados Influênciados por calagem e Concentrações de Metais em Latossolo Vermelho-Amarelo. Viçosa, MG: UFV, 1996. 161p. Tese Doutorado Universidade Federal de Viçosa, 1996.

GONÇALVES, J.L. de M.; VAZ, L.M.S.; AMARAL, T.M.; POGGIANI, F. Aplicabilidade de biossólido em plantações florestais: II Efeito na fertilidade do solo, nutrição e crescimento das árvores. In: BETTIOL, W. \& CAMARGO, O.A. (ed.). Impacto ambiental do uso agrícola do lodo de esgoto. EMBRAPA - Meio Ambiente e IAC, 2000. p. 179-95.

GUIDI, G.V.; PETRUZZELLI, G.; VALLINI, G.; PERA, A. Plant productivity and heavy metal contamination. Biocycle, $13: 46-48,1990$.

HENSLER, R.F.; OLSEN, R.J.; ATTOE, ' J. Effect of soil $\mathrm{pH}$ and application rate of dairy cattle manure on yield and recovery of twelve plant nutrients by com. Agronomy Journal, 62:828-30, 1970. 
HINSINGER, P. Bioavailability of trace elements as related to root-induced chemical changes in the rhizosfere. In: INTERNATIONAL CONFERENCE ON THE BIOGEOCHEMISTRY OF TRACE ELEMENTS, 5., 1999, Viena. Proceedings... Viena: International Society for Trace Element Reserach, 1999. p. 152-153.

HOODA, P.S.; ALLOWAY, B.J. The effect of liming on heavy metal concentrations in wheat, carrots and spinach grown on previously slude applied soils. Journal of Agricultural Science, 127:289-94, 1996.

HOSONO, M.; RII, P.; TACHIBANA, Y.; OHTA, Y. Alleviation by heavy metal toxicities in crop planta. (II) Effects of calcium concentration in nutrient solutions on heavy metal accumulation in rice and tomato plants. Journal of the Science and Manure, 50:358-360, 1979. Resumo em CAB Abstract on CD-ROM, 1979-81.

HOYT, P.B. Effects of organic matter content on exchangeable $\mathrm{Al}$ and $\mathrm{pH}$ dependent acidity of very acid soils. Can. J. Soil Sci., 57:221-22, 1977.

HOYT, P.B.; TURNER, R.C. Effect of organic materials added to very acid soil, on $\mathrm{pH}$, aluminum, exchangable $\mathrm{NH}_{4}^{+}$, and crop yields. Soil Sci., 119:227-37, 1975.

HUANG, J.W.; SHAFF, J.E.; GRUNES, D.L.; KOCHIAN, L.V. Aluminum effects on fluxes at the root apex of aluminum-tolerant and aluminum-sensitive wheat cultivars. Plant Physiology, 98:230-37, 1992.

HUE, N.V. \& AMIEN, I. Aluminum detoxification with green manures. Comm. Soil Sci. Pl. Am., 20:1499-1511, 1989.

HUE, N.V.; SILVA, J.A.; ARIFIN, R. Sewage sludge-soil interactions as measured bu plant and soil chemical composition. J. Environ. Qual., 17:384-90, 1988. 
KABATA-PENDIAS, A \& H. PENDIAS. Trace Elements in Soils and Plants. Boca Ratona, Flórida, CRC Prez, 1984. 315p.

KABATA-PENDIAS, A.; PENDIAS, $H$. Trace elements in soil and plants. 3. ed. Boca Raton: CRP Press, Inc., 1985. 315 p.

KIEHL, E.J. Fertilizantes orgânicos. Piracicaba, Agronômica Ceres. 1985. 492p.

KING, L.D. Soil heavy metals. In: ALVAREZ, V.H.; FONTES, L.E.F.; FONTES, M.P. (Ed.) O solo nos grandes domínios morfoclimáticos do Brasil. Viçosa: SBCS, 1996. p. 823-836.

KING, L.D.; HAJJAR, L.M. The residual effect of sewage slude on heavy metal content of tobacco and peanuts. Joumal of Environmental Quality, 19:738$748,1990$.

KING, L.D.; MORRIS, H.D. Land disposal of liquid sewage slude. II. The effect on soil $\mathrm{pH}$, manganese, zinc and growth and chemical composition of rye (Secale cereale L.). J. Environ. Qual., 1:425:29, 1972.

KINNIBURGH, D.G.; JACKSON, M.L.; SUERS, J.K. Adsorption of alkaline earth, transition, and heavy metal cations by hidrous oxide gels of iron and aluminum. Soil Sci. Soc. Am. J., 40:796-99, 1976.

KRISHNAMURTI, G.S.R.; CIESLINSKI, G.; HUANG, P.M.; VaNREES, K.C.J. Kinetics of cadmium release from soils as influenced by organic acids: implication in cadmium availability. Journal of Environmental Quality, 26:271-77, 1997.

LIDSAY, W.P. Chemical equilibria in soils. Wiley - Interscience, New York, 1979. 449p.

LOTHENBACH, B.; FURRER, G.; SCHULIN, R. Immobilization of heavy metals by polynuclear aluminium and montmorillonite compounds. Environmental Science Technology, 31:1452-62, 1997. 
LUND, Z.F.; DOSS, B.D. Residual effect of dairy cattle manure on plant growth and soil properties. Agronomy Journal, 72:123-30, 1980.

MALAVOLTA, E. Elementos de nutrição mineral de plantas. Ed. Agtonômica Ceres, São Paulo, 1980. 251 p.

MALAVOLTA, E. Fertilizantes e seu Impacto Ambiental: Micronutrientes e Metais Pesados, Mitos, Mistificação e fatos. São Paulo. ProduQuímica, 1994. 153p.

MALAVOLTA, E. Manual de química agrícola. Ed: Agronômica Ceres, 1976, 528p.

MALAVOLTA, E; KLIEMANN, H.J. Desordens nutricionais no cerrado. Piracicaba: Associação Brasileira para Pesquisa da Potassa e do Fosfato, 1985. $136 \mathrm{p}$.

MATIAZZO-PREZOTTO, M.E. Comportamento de cobre, cádmio, crômio, níquel e zinco adicionados a solos de clima tropical em diferentes valores de pH. Piracicaba: ESALQ-USP, 1994. 197p. Tese Livre-Docência.

MATIAZZO-PREZOTTO, M.E.; 'CRUZ, M.C.P. da; BERTON, R.S. Disponibilidade e avaliação de metais pesados potencialmente tóxicos. In: FERREIRA, M.E., ed. Micronutrientes e elementos tóxicos na agricultura. Jaboticabal, 1998. (No prelo).

McGRATH, S.P.; CEGARRA, J. Chemical extractability of heavy metals during and after long-term application of sewage slude to soil. Journal of Soil Science, 43:313-21, 1992.

MELLO, F.A. de; BRASIL SOBRINHO, M.O.C. de; ARZOLLA, S.; SILVEIRA, R. I.; COBRA NETO, A.; KTEHEL, J.C. Fertilidade do solo. 3 ed. Nobel, 1989. 400p. 
MELO, W.J. de; MARQUES, M.O.; SILVA, F.C. da; BOARETTO, A.E. Uso de resíduos urbanos na agricultura e impactos ambientais. In: CONGRESSO BRASILEIRO DE CIÊNCIA DO SOLO, 26. Rio de Janeiro. Resumos... 1997.

MENCH, M.; MARTIN, E. Mobilization of cadmium and other metals from two soils by root exudates of Zea mays L., Nicotiana tabacum L and Nicotiana rustica L. Plant and Soil, 132:187-96, 1991.

MENGUEL, K \& KIRKBY, E.A. Principles of plant nutrition. 4 ed. International Potash Institute, 1987. 687 p.

MERCKX, R.; VANGINKEL, J.H.; SINNAEVE, J.; CREMERS, A. Plant-induced changes in the rhizosphere of maize and wheat. II Complexation of cobalt, zinc and manganese in the rhizosphere of maize and wheat. Plant and soil, 96:95-108, 1986.

MESQUITA FILHO, M.V. \& SOUZA, A.F. Resposta do tomateiro à aplicação da calagem e da adubação fosfatada. In: CONGRESSO BRASILEIRO DE OLERICULTURA, 26. Salvador, 1986. Resumos. Horticultura Brasileira, Brasilia, 4:61, 1986.

MIYAZAWA, M.; PAVAN, M.A.; CALEGARI, A. Efeito de material vegetal na acidez do solo. $\mathbf{R}$. bras. Ci. Solo, 17:411-416, 1993.

MIYAZAWA, M.; PAVAN, M.A.; FRANCHINI, J.C. Moléculas orgânicas relacionadas a química e a fertilidade do solo. In: FERTIBIO 2000, REUNIÃO BRASILEIRA DE FERTILIDADE DO SOLO E NUTRIÇÃO DE PLANTAS, 24. Santa Maria, RS. 2000. Resumo em CD-ROM, 2000.

MORTVEDT, J.J. Plant uptake of heavy metals in zinc fertilizers made from industrial by products. Journal of Environmental Quality, 14:424-27, 1985. 
NUERNBERG, N.J.; STAMMEL, J.G. Rendimento de culturas e características químicas do solo sob diferentes sucessões e adubação orgânica e mineral. $\mathbf{R}$. bras. Ci. Solo, 13:87-93, 1989.

PAGE, A.L. ed. Methods of soil analysis; pt 2 Chemical and microbiological properties. Madison, Am. Soc. Agronomy, 1982. 1159 p.

POWELL, P.E.; LINE, G.R. \& REID, C.P.P. Ocurrence of hydroximath siderophore iron chelators in soils. Nature, London, 287:833-34, 1981.

PRATA, F. Biodegradação e adsorção dos herbicidas diuron e ametrina em solos tratados com vinhaça. Piracicaba: ESALQ-USP, 1998. Dissertação Mestrado. 73p.

RAIJ, B. van. Avaliação da fertilidade do solo.3 ed. Potafos, 1987. 142p.

RAIJ, B. van. Fertilidade do solo e adubação. Agronômica Ceres, 1991. 343p.

REIS, T.C.; RODELLA, A.A.; relação entre a incorporação de matéria orgânica, $\mathrm{pH}$ e alumínio trocável do solo. In: REUNIÃO BRASILEIRA DE FERTILIDADE DO SOLO, 22. Caxambú, 1998. Anais... Caxambú: SBCS, 1998, p.382.

RENGEL, Z.; ROBINSON, D.L. Competitive $\mathrm{Al}^{3+}$ inhibition of net $\mathrm{Mg}^{2+}$ uptake by intac Lolium multiflorum toots. I Kinetics. Plant Physiology, 91:1407-13, 1989.

RODELLA, A.A; ALCARDE, J.C Avaliação de materiais orgânicos empregados como fertilizantes. Scientia Agrícola, v.51, n.3, p. 556-562, 1994.

SANDERS, J.R \& SPARKS, D.L. Environmental soil chemistry. San Diego: Califomia, 1995. Cap.5, p.99-139.

SANTILllaN-MEDRANO, J.; JURINAK J.J. 1975. Soil Sci Soc Am Proc., 39:851-56. 
SINGH, A.K; PANDEYA, S.B. Sorption and release of cadmium-fulvic acid complexes in sludge treated soils. Bioresource Technology, 66:119-27, 1998.

SIQUEIRA, R.N.B. Competição e extração seletiva de ions metálicos associados a ácidos húmicos. Viçosa-MG, UFV, 1987. 82p. (Dissertação Mestrado).

SPOSITO, G. The chemistry of soils. New York, Oxford University Press, 1989. 277p.

TAN, K.H. Principles of soil chemistry, second edition. Marcel Dekker, Inc. New York., 362 p. 1993.

TESSIER, A.; CAMPBELL, P.G.C.; BISSON, M. Sequential extraction procedure for the speciation of particulate trace metals. Anal. Chem., 51:844-851, 1979

TISDALE, S.L.; NELSON, W.L. \& BEATON, J.D. Soil fertility and fertilizers. 4 ed. Macmillan, 1985. 754 p.

TYLER, G., PAHLSSON, M.B., BAATH, B.E. et al. Heavy-metal ecology of terrestrial plants, microorganisms and invertebrates. A review. Water, Air, and Soil Pollution, Dordrecht, 47:189-215, 1989.

VELOSO, C.A.C.; BORGES, A.L.; MUNIZ, A.S.; VEIGAS, I.A. de J.M. Efeito de diferentes materiais no pH do solo. Scientia Agrícola, v. 49, n.1, p. 123-128, 1992.

XIAN, X. Effect of chemical forms of cadmium, zinc, and lead in polluted soils on their uptaka by cabbage plants. Plant and Soil, 113:257-264, 1989. 